\title{
Erdbebenberichte und Diskurse der Kontinuität in der postformativen Periode
}

\author{
Konrad Hirschler (London)
}

Katastrophen können neben materiellen Schäden entscheidende Veränderungen in der Struktur und Organisation einer Gesellschaft hervorrufen. Diese Veränderungen sind insbesondere in der kollektiven Identität einer sozialen Gruppe wahrnehmbar, die durch die Katastrophe einer extremen Diskontinuität gegenübersteht. Der Einschnitt zwischen einem „Vorher" und einem „Hinterher" kann als ein Wendepunkt erfahren werden, der die bisherigen individuellen und kollektiven Erfahrungen in Frage stellt. Auf eine solche Diskontinuität können Gesellschaften mit unterschiedlichen Mustern reagieren. Der Einschnitt kann als Neubeginn dargestellt werden, mit dem die Gruppe in eine vollkommen neue Ära eintritt oder er kann als Teil einer weiter bestehenden Identität aktiv in die gesellschaftliche Erinnerungsarbeit miteinbezogen werden. Weiterhin kann ihm mit einem Muster begegnet werden, das die eingetretenen Veränderungen marginalisiert, die Bedeutung des Einschnitts mindert und damit auf die Wiederherstellung von Kontinuität abzielt. ${ }^{1}$

Im Folgenden werden arabischsprachige Texte der postformativen Periode, genauer vom 5./11. bis zum 11./18. Jahrhundert, in Hinblick darauf untersucht, welche Reaktionen auf Erdbeben in ihnen deutlich werden. Dabei wird gezeigt, dass die untersuchten Texte tendenziell dem obigen Muster der Wiederherstellung von Kontinuität folgten. Dieses

1) A. Cavalli: Gedächtnis und Identität. Wie das Gedächtnis nach katastrophalen Ereignissen rekonstruiert wird, in: K. E. MÜLle R/J. Rüsen (Hg.): Historische Sinnbildung, Problemstellungen, Zeitkonzepte, Wahrnehmungshorizonte, Darstellungsstrategien, Reinbek (Hamburg) 1997, 455-70, hier: 458-61. Dieser Artikel basiert auf einem Beitrag zum Workshop Lokales Handeln in Katastrophensituationen: Muslime angesichts der Katastrophe an der Universität Bayreuth. Ich danke Roman Loimeie R für die Einladung zur Teilnahme, den TeilnehmerInnen für ihre Anregungen und Fragen zum Vortrag sowie Anja Pistor-Hatam (Kiel) für die vielfältigen Anmerkungen zum Artikel. 
Muster war in den hier betrachteten Literaturgattungen, Chroniken und Erdbebenabhandlungen, so hegemonial, dass es als „Diskurs der Kontinuität" bezeichnet werden kann. Die Gemeinsamkeit der Texte, die in diesen Diskurs eingebettet waren, bestand darin, dass sie die einschneidende Erfahrung im kollektiven Gedächtnis zu „domestizieren“ beabsichtigten. Entsprechende Berichte zu Erdbeben dienten somit nicht vorrangig dem Ziel, die Katastrophen und ihre Folgen zu beschreiben, sondern sollten dem Leser angesichts der Schrecken dieser Katastrophen mittels des Diskurses der Kontinuität Gewissheit und Versicherung geben. Passagen, die etwa in Chroniken von Erdbeben handeln, sind somit in erste Linie nicht als deskriptive, sondern als normative Texte zu verstehen. Eine solche Sichtweise auf Erdbebenberichte erlaubt es, den Aufbau und die Besonderheiten dieser Berichte zu verstehen, insbesondere die Armut an faktischem Material.

„Diskurs“ wird hier im Sinne der historischen Diskursanalyse verstanden, soweit sie sich aus den Überlegungen Foucaults entwickelt hat. ${ }^{2}$ Ausgangspunkt der Analyse ist dabei, dass zu einem bestimmten Zeitpunkt oder über eine längere Periode nur eine begrenzte Menge von Aussagen zu einem Thema gemacht werden, obwohl potenziell eine unendliche Menge von Aussagen existiert. Die Möglichkeit dessen, was ausgesagt werden kann, unterliegt dabei nicht dem Zufall, sondern - ebenso wie die Unmöglichkeit spezifische Aussagen zu treffen - einem Diskurs. Die Regeln und RegelmäBigkeiten, die gesellschaftliche Verankerung und die Veränderungen dieses Diskurses sind Gegenstand der historischen Diskursanalyse. In Anlehnung hieran wird im Folgenden vorrangig gezeigt, in welchen Texten, beziehungsweise Literaturgattungen Aussagen zu Erdbeben gemacht werden konnten, und inwieweit diese Aussagen im Rahmen des Diskurses der Kontinuität Regelmäßigkeiten (und Differenzen) inhaltlicher Natur aufwiesen.

Der Diskurs der Kontinuität wird dabei als die Gesamtheit der Aussagen zu Erdbeben in Chroniken und Erdbebenabhandlungen verstanden. Dieser Diskurs grenzte das Sagbare ein und bändigte somit die Gefahr der Unordnung und des Unkontrollierten, die der Katastrophe inne wohnte. Diese Eingrenzung stellt sich zum Beispiel in der Form dar, dass Erdbebenberichte eine schablonenhafte Struktur aufweisen, so dass Details über ein spezifisches Erdbeben häufig kaum ausgemacht werden

2) Hierzu vgl. P. Sarasin: Geschichtswissenschaft und Diskursanalyse, Frankfurt/Main 2003; M. Maset: Diskurs, Macht und Geschichte. Foucaults Analysetechniken und die historische Forschung, Frankfurt/Main 2002; A. LANDwEHR: Geschichte des Sagbaren. Einführung in die historische Diskursanalyse, Tübingen 2001. 
können. Diese schablonenhafte Struktur marginalisierte soziale Umwälzungen und drückte selbst spirituelle Reaktionen lediglich in einer standardisierten Terminologie aus. Der Diskurs der Kontinuität konnte zwar keine Ausschließlichkeit beanspruchen, da in anderen Literaturgattungen von diesem Diskurs abweichende Aussagen möglich waren. Gleichzeitig nahm er jedoch eine herausgehobene Stellung ein, da er in zwei entscheidenden Literaturgattungen, Erdbebenabhandlungen und Chroniken, hegemonial war. Diese diskursive Strategie in Bezug auf Erdbeben tritt insbesondere in den Erdbebenabhandlungen zu Tage, da sie in gröBerer Ausführlichkeit als die Chroniken Auskunft über Sichtweisen auf diese Katastrophenform geben.

Erdbeben spielten in den Literaturen nahöstlicher Gesellschaften eine herausgehobene Rolle, da sie neben Hungersnöten und Seuchen zu den „Natur"katastrophen zählten, die für Menschen in zahlreichen Regionen aufgrund ihrer hohen Opferzahlen und starken Zerstörungskraft eine Gefahr darstellten. ${ }^{3}$ Das Bewusstsein der Allgegenwärtigkeit von

$\left.{ }^{3}\right)$ Bisherige Arbeiten zur Geschichte dieser Katastrophenform im Nahen Osten umfassen in erster Linie Editionen und Übersetzungen relevanter Texte (so zum Beispiel die im Folgenden diskutierten Erdbebenabhandlungen von asSuyūṭi: Kašf aṣ-ṣalṣala can waṣf az-zalzala, hg. v. Muḥammad Kamāl ad-Dīn 'Izz AD-Dīn, Beirut: 'Ālam al-kutub, 1987 (Notizen/Fortsetzungen hierzu auf dem MS

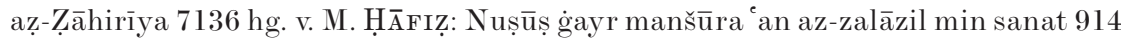
wa-ḥattā sanat 1124 (h)/1508-1712, in: Bulletin d'Etudes Orientales 32-33 (1980-81), 256-64; Ḥāmid b. 'Alī al- Imādī: al-Ḥawqala fī az-zalzala, hg. v. M. A. TAHer: Textes d'historiens damascènes sur les tremblements de terre, in: Bulletin d'Etudes Orientales 27 (1974), 51-108, hier: 59-65 and 'Alī b. Muḥammad Ibn alĞazzār: Tahṣinn al-manāzil min hawl az-zalāzil, hg. v. M. A. Ṭ̂AHIR: Traité de la fortification des demeures contre l'horreur des séismes, in: Annales Islamologiques 12 (1974), 131-59), Erdbebenkataloge sowie Beiträge mit geologischem Schwerpunkt (so inbesondere N. N. Ambraseys/C. P. Melville: A History of Persian Earthquakes, Cambridge 1982; N. N. Ambraseys/C. P. Melville/R. D. Adams: The Seismicity of Egypt, Arabia and the Red Sea. A Historical Review, Cambridge 1994; M. A. TAHER: Les grandes zones sismiques du monde musulman à travers l'histoire, in: Annales Islamologiques 30 (1996), 79-104; C. Me Lville: ,zalzala“, in: Encyclopaedia of Islam. New Edition, 11 Bd., WebCD edition (Leiden 2003). Historische Beiträge zum Thema finden sich dagegen lediglich im geringen Maße. Genannt sei hier D. P. Little: Data on Earthquakes Recorded by Mamluk Historians: A Historiographical Essay, in: E. Zachariadou (Hg.): Natural Disasters in the Ottoman Empire: Halcyon Days in Crete III: A Symposium Held in Rethymnon 10-12 January 199\%, Rethymnon: Crete University Press 1999, 137-44. R. Schulze: Islamische Deutungen von Erdbeben und anderen Naturkatastrophen, in: C. Pfiste R/S. Summermatter (Hg.): Katastrophen und ihre Bewältigung. Perspektiven und Positio- 
Erdbeben drückte sich bereits darin aus, dass die muslimische Gemeinschaft in der Erzählung ihrer Genese dieser Katastrophenform Raum einräumte. So soll die Geburt des Propheten Muhammad von einem Erdbeben begleitet gewesen sein, das die Götzen in Mekka und Kirchen zerstörte, sowie den Palast des sāsānidischen Herrschers in Persien beschädigte. ${ }^{4}$ Das fünfte Jahr des islamischen Kalenders trug zudem die Bezeichnung „Jahr des Erdbebens“.5 Im gleichen Sinne verbanden Autoren entscheidende Ereignisse der Heilsgeschichte vor der Sendung des Propheten Muḥammad mit Erdbeben: So waren gemäß der Überlieferung sowohl die göttliche Prüfung Abrahams als auch die Bestrafung derjenigen, die Moses Ermahnungen nicht folgten, von Erdbeben begleitet. ${ }^{6}$ Verweise auf Erdbeben finden sich ebenfalls im Qur'ān, der eigens eine Erdbeben-Sure (Sure 99, surat az-zalzala) enthält, und in hadițen, die Erdbeben als Strafe für die Ungläubigen und die sündigen Muslime sowie als Ankündigung des Jüngsten Gerichts erwähnen.

Eine Betrachtung der geologischen Verhältnisse des Nahen Ostens zeigt jedoch, dass in den einzelnen Regionen unterschiedlich starke Grade der Erdbebengefährdung vorliegen. ${ }^{7}$ Eine hohe Seismizität be-

nen, Bern/Stuttgart/Wien 2004, 101-17 diskutiert die Erdbebenabhandlungen asSuyūṭis und Ibn al-Ǧazzārs im Rahmen von Überlegungen zur naturkundlichen und religiösen Erklärungsmustern für diese Naturkatastrophe. Die hervorragende Arbeit von A. Akasoy: Islamic Attitudes to Disasters in the Middle Ages: A Comparison of Earthquakes and Plagues, in: The Medieval History Journal 10/1-2 (2007), 387-410 konnte nicht mehr in die Diskussion einbezogen werden.

$\left.{ }^{4}\right)$ al-Ya ${ }^{e} q \bar{u} b \overline{1}:$ Ta’̀īh al-Ya $a^{e} \bar{u} b \bar{\imath}, 2$ Bd., Beirut: Dār Șādir/Dār Beirut, 1960, hier: II, 8; as-Suyūṭī, Kašf, 163-64; al-Bayhaqī: Daläill an-nubūwa wa-márifat

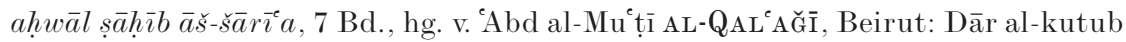
al-ilmīya, 1985, hier: I, 126. Vergleichbar hiermit ist das Erdbeben, das laut Matthäus 27:51 ff. während der Kreuzigung Jesus Christi auftrat.

$\left.{ }^{5}\right)$ al-Bīrūnī: al-Ațār al-bāqiya can al-qurūn al-ḩāliya, hg. v. E. SACHAU, Leipzig 1876,31 .

$\left.{ }^{6}\right)$ as-Suyūṭī $K a \check{s} f, 157,159-60$.

$\left.{ }^{7}\right)$ Zur Seismizität des Nahen Ostens generell vgl. S. SchöLER: Aktuelle und historische Seismizität im Vorderen und Mittleren Orient. Einführung in die TAVO Karte AII 13: „Vorderer Orient. Seismotektonik und geschichtliche Beben“, Wiesbaden 1992. Die Diskussion zahlreicher Erdbeben im Osmanischen Reich zwischen 1690 und 1710 von N. N. Ambraseys/C. F. Finkel: The Seismicity of the Eastern Mediterranean Region during the Turn of the Eighteenth Century, in: Istanbuler Mitteilungen 42 (1992), 323-43 zeigt beispielhaft wie genaue Informationen über die zahlreichen Erdbeben eines so kurzen Zeitraums gewonnen werden können. 
steht in weiten Gebieten Anatoliens, insbesondere entlang der Nordanatolischen Horizontalverschiebung, an der die Türkische an die Eurasische Platte grenzt. So gehörte das Erdbeben im Marmara-Meer im Jahre 915/ 1509 mit einer geschätzten Oberflächenwellen-Magnitude von MS>7,4 zu den stärksten Erdbeben der letzten fünf Jahrhunderte im östlichen Mittelmeerraum. ${ }^{8}$ Weiter östlich führt insbesondere die Plattengrenze zwischen der Arabischen und der Eurasischen Platte, die den heutigen Iran vom Südwesten bis zum Nordwesten durchzieht, zu einer Erdbebengefährdung. ${ }^{9}$ Andere Regionen des Nahen Ostens gehören jedoch zu den seismisch stabilsten Regionen der Erde, so etwa die arabische Halbinsel mit Ausnahme des Jemen und des Ḥiğāz.

Auch Ägypten und Syrien, die im Folgenden im Mittelpunkt stehen, haben aufgrund der Grenze zwischen der Arabischen und der Afrikanischen Platte, die vom Roten Meer im Süden bis ins südöstliche Anatolien reicht, regelmäßig Erdbeben erlebt. ${ }^{10}$ Die angrenzenden Gebiete weisen aber, zumindest seit Beginn der Instrumentenmessung, lediglich eine moderate Seismizität auf. ${ }^{11}$ Im nordwestlichen Syrien etwa, das am nördlichen Ende dieser Plattengrenze liegt, sind schwere Erdbeben im Durchschnitt alle $360 \pm 60$ Jahre sowie Erdbeben mittlerer Stärke alle $17 \pm 51$ Jahre zu erwarten. ${ }^{12}$ In Ägypten sind die an das Rote Meer und den Golf

${ }^{8}$ ) N. N. Ambraseys/C. F. Finkel: The Marmara Sea Earthquake of 1509, in: Terra Nova (Oxford) 2 (1990), 167-74. Zu Erdbeben im Gebiet der heutigen Türkei von 1500-1800 vgl. N. N. Ambraseys/C. F. Finkel: The Seismicity of Turkey and Adjacent Areas. A Historical Review, 1500-1800, Istanbul: Eren, 1995.

$\left.{ }^{9}\right) \mathrm{Zu}$ Erdbeben in Persien vgl. Ambraseys/Melville, Persian Earthquakes. C. P. Melville: Earthquakes in the History of Nishapur, in: Iran 18 (1980), 103-22 und C. P. Melville: Historical Monuments and Earthquakes in Tabriz, in: Iran 19 (1981), 159-77 behandeln beispielhaft Erdbeben während der islamischen Periode.

$\left.{ }^{10}\right)$ Hierzu vgl. Ambraseys/Melville/Adams, Egypt, Arabia and the Red Sea. „Ägypten“ und „Syrien“ sind im Folgenden stets im Sinne der zeitgenössischen Begriffe „ad-Diyār al-Miṣrīya" und "aš-Šām" gemeint.

11) Ambraseys/Melville/Adams, Egypt, Arabia and the Red Sea. N. N. AmBRAseys: Temporary Seismic Quienscence: SE Turkey, in: Geophysical Journal 96 (1989), 311-31 zeigt jedoch, dass zum Beispiel Erdbeben am nördlichen Ende der Plattengrenze in Ostanatolien vor dem Beginn der Instrumentenmessung häufiger waren. K. W. Russell: The Earthquake Chronology of Palestine and Northwest Arabia from the $2^{\text {nd }}$ through the Mid- $8^{\text {th }}$ Century A. D, in: Bulletin of the American Schools of Oriental Research 260 (1985), 37-59.

12) J. P. Poirier/B. A. Romanowicz/M. A. Taher: Large Historical Earthquakes and Seismic Risk in Northwest Syria, in: Nature 285 (1980), 219-20. 
von Suez angrenzenden Gebiete ebenfalls regelmäßig von Erdbeben betroffen. Das Binnenland hingegen ist durch eine geringere Seismizität charakterisiert, erlebt aber dennoch unregelmäßige und starke Erdbeben.

\section{Erdbebenberichte in Chroniken}

In den annalistischen Chroniken wurden katastrophale Ereignisse meist am Ende des jeweiligen Jahres erwähnt. In den entsprechenden Abschnitten fassten die Autoren allerdings eine Vielzahl von Vorkommnissen zusammen, die sich einer Rubrizierung unter dem Begriff „Katastrophe“ im heutigen Sinne entziehen. Neben Ereignissen wie Seuchenausbrüchen, Hungersnöten, Erdbeben, extremen Temperaturschwankungen oder Stürmen finden sich auch Sonnenfinsternisse, Meteoritenstürme oder aufsehenerregende Missgeburten. Den letzteren Vorkommnissen wurde ebenso wie in anderen Kulturen der Vormoderne ${ }^{13}$ - ebenfalls die Funktion zugeschrieben, als Mittel der Kommunikation zwischen der irdischen und der überirdischen Sphäre zu dienen. Damit galten sie als gleichwertige Akte göttlicher Kommunikation, durch die etwa die Sünder bestraft und die Rechtschaffenden ermahnt werden sollten.

Nur wenn Katastrophen besonders gravierende Folgen hatten, gestanden die Chronisten ihnen einen eigenen Bericht zu, wie etwa dem Erdbeben im Jahre 552/1157 in Syrien. ${ }^{14}$ Diese Berichte waren zwar ausführlicher als die Einträge in den „Katastrophen“abschnitten am Ende

13) Vgl. G. H. WALDhe RR: Erdbeben-das außergewöhnliche Normale. Zur Rezeption seismischer Aktivitäten in literarischen Quellen vom 4. Jahrhundert v. Chr. bis zum 4. Jahrhundert n. Chr., Stuttgart 1997, 221-39 für die griechisch-römische Antike und M. Merer: Perceptions and Interpretations of Natural Disasters during the Transition from the East Roman to the Byzantine Empire, in: The Medieval History Journal 4 (2001), 179-202, hier: 181-82 für die Spätantike.

14) Abū Šàma: Kitāb ar-rawḍtayn fī ahbār ad-dawlatayn an-Nūūya wa-așȘalāḥ̄ya, 5 Bd., hg. v. Ibrāhīm Az-Zīiaq, Beirut: Mu’assasat ar-risāla, 1997, I, 332-39; Ibn al-Ațīr: al-Kāmil fī at-ta’rìh, 13 Bd., Beirut: Dār Șādir, 1965-67, XI, 218; Ibn al-Ațîr: at-Ta'rīh al-bāhir fī ad-dawla al-atābakīya, hg. v. 'Abd al-Qādir A. Țulaymāt, Kairo: Dār al-kutub al-ḥadịta, 1963, 110; Ibn Wāṣil: Mufarriğg al-

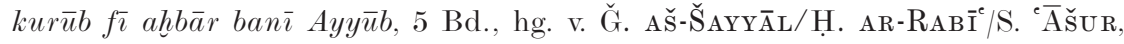
Kairo: Mațba at ğāmic at Fu'ād al-awwal u.a., 1953-77, I, 128; a d al-Islām wa-wafayāt al-mašăhīr wa-al-a lām, 52 Bd., hg. v. ${ }^{e} \mathrm{U}$. 'Abd as-Salām TADMurī, Beirut: Dār al-kitāb al- 'arabī, 1994-2000, Jahre 551-60, 17-18; Ibn alQalānisī: Dayl ta’rīh Dimašq, hg. v. H. F. Amedroz, Leiden 1908, 337, 343-47, $351-52$. 
des jeweiligen Jahres, zeichneten sich jedoch durch ihre schablonenhafte Form aus. Sie gaben daher kaum Auskunft über Einzelheiten und genauere Sachverhalte. Das einzige Thema, dem sie generell mehr Beachtung schenkten, war das Ausmaß der Zerstörungen an zentralen Gebäuden, wie Moscheen und Zitadellen. Dagegen fehlten ausführlichere Beschreibungen der Folgen für die betroffene Bevölkerung. Die Angaben zu Opferzahlen - sofern überhaupt angegeben - waren häufig sehr hoch, für das Erdbeben von 598/1202 zum Beispiel wurden allein für Nablus 30.000 und für Ägypten 1.100.000 Opfer angegeben. ${ }^{15}$ Die Vermutung, dass es sich hierbei - wie auch bei den Angaben zu Opfern von Seuchenausbrüchen - tendenziell um symbolische Angaben handelte, liegt nahe. ${ }^{16}$ Einen genaueren Eindruck von Opferzahlen könnten wohl bestenfalls quantitative Arbeiten zu biographischen Lexika bieten. Denn entgegen der verbreiteten Einschätzung, dass diese mit Ausnahme von Seuchenausbrüchen kaum katastrophenbedingte Todesfälle erwähnten, erscheint eine Untersuchung dieser Lexika durchaus vielversprechend. ${ }^{17}$

Ein typisches Beispiel für einen Erdbebenbericht am Ende eines Jahres lautet: „Und in diesem Jahr wurde Persien, vom Irak bis jenseits von ar-Rayy, von einem Erdbeben erschüttert. Viele Menschen verloren ihr Leben und viele Bauwerke wurden zerstört. Es war am stärksten in arRayy und Qazwīn." 18 Selbst bei den Erdbeben, die die Region des jewei-

$\left.{ }^{15}\right)$ Sibț b. al-Ğawzī: Mir'āt az-zamān fī ta'rīh al-a yān, 4 Bd., Hyderabad: Mațba ât mağlis dāirat al-ma ārif al-'Uțmānīya, 1954-60, VIII/2, 478.

$\left.{ }^{16}\right)$ Zur symbolischen Aussagekraft von solchen Zahlenangaben vgl. L. I. CoNRAD: Seven and the tasbí: On the Implications of Numerical Symbolism for the Study of Medieval Islamic History, in: Journal of the Economic and Social History of the Orient 31 (1988), 42-73.

$\left.{ }^{17}\right) \mathrm{Zu}$ dieser Einschätzung vgl. W. Tucke R: Environmental Hazards, Natural Disasters, Economic Loss, and Mortality in Mamluk Syria, in: Mamlūk Studies Review 3 (1999), 109-28, hier: 110-11. Dagegen werden in Lexika wie Ibn 'Asākirs Madīnat Ta’rīh Dimašq katastrophenbedingte Todesfälle regelmäßig erwähnt. So nannte er zum Beispiel im Zusammenhang mit dem syrischen Erdbeben des Jahres 552/1157 allein für das nordsyrische Hama die Gelehrten 'Alī Abū al-Hasan atTanūhī (Ibn 'Asākir: Ta’rīh madīnat Dimašq, hg. v. Șalāḥ ad-Dīn AL-MunaĞĞID/ Sukayna Aš-šıHĀBī et al., Damaskus: Mağma al-lugga al-'arabìya bi-Dimašq/ Mu'assasat ar-risāla, 1951 ff., hier: LI, 227-31) und den Dichter 'Abd ar-Raḥmān b.

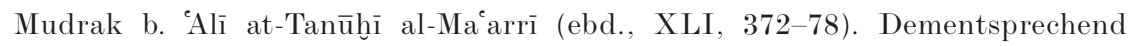
könnte eine systematische Untersuchung biographischer Lexika dazu beitragen, die Folgen spezifischer Katastrophen zumindest für die Elite besser einschätzen zu können.

18) Ibn al-Ațīr, Kāmil, XI, 433 (Jahr 571/1175-6). 
ligen Autors unmittelbar betreffen und zu denen sicherlich mündliche Berichte von Augenzeugen kursierten, waren entsprechende Berichte eher knapp: „In der Nacht des 27. D̄ū al-Ḥiğğa [608/1212] kam es zu einem enormen Erdbeben, das viele Lokalitäten in Mișr und al-Qāhira zerstörte sowie Türme und Häuser in al-Karak und aš-Šawbak. Viele Kinder und Frauen starben unter den Trümmern. Sein Epizentrum war in $(q \bar{u}$ watuhā min ǧihat) Ayla am Meer (heutiges al-Aqaba in Jordanien). Es wird gesagt, dass ihm ein schwarzer Wind und Sternschnuppen vorausgingen." 19

Bei detaillierten Informationen zu spezifischen Ereignissen handelte es sich oft um Anekdoten, die dann eine Vielzahl von unterschiedlichen Chroniken nahezu gleichlautend reproduzierte. So wurde zum Beispiel in Hinblick auf das Erdbeben im Jahre 552/1157 von den meisten Autoren des folgenden Jahrhunderts die gleiche Anekdote eines Lehrers überliefert, der unmittelbar vor dem Erdbeben seine Schule kurz verlassen hatte. Seine gesamte Schülerschaft starb unter den Trümmern des zusammenstürzenden Gebäudes. Dennoch kam in den Folgemonaten nicht ein einziger Verwandter, um sich nach dem Schicksal der Kinder zu erkundigen, was die Autoren als Beleg für die hohen Opferzahlen ansahen. ${ }^{20}$ Dieses anekdotische Material spielte, wie zum Abschluss dieses Artikels gezeigt werden wird, eine wichtige Rolle in der narrativen Ausgestaltung von Erdbebenberichten.

In den Chroniken wurden hinsichtlich der Reaktionen der Bevölkerung - so sie denn angesprochen werden - generell zwei Aspekte angesprochen. Einerseits fanden praktische Überlebensstrategien von Individuen angesichts der Katastrophe Erwähnung. Genannt wird hier die Flucht in unbebautes Gelände und gelegentlich das Errichten von Hütten und Zelten zur vorübergehenden Unterbringung. ${ }^{21}$ Andererseits treten in den Chroniken in Bezug auf die Reaktionen der Bevölkerung Elemente der

19) Abū Šāma: ad- $\underline{\text { Dayl }}{ }^{\text {c } a l a ̄ ~ a r-r a w d ̣ t a t a y n ~(h e r a u s g e g e b e n ~ u n t e r ~ d e m ~ T i t e l: ~} T a$ -

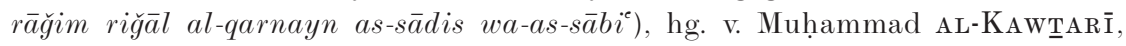
Kairo: Maktab našr aț-taqāfa al-islāmīya, 1947, 78.

${ }^{20}$ ) Ibn al-Ațīr, Kāmil, XI, 218 und Bāhir, 110; Ibn Wāṣil, Mufarriğ, I, 128; Abū al-Fidā': al-Muhtaṣar f̄̃ ahbār al-bašar, 4 Bd., Kairo: al-Maṭba a al-ḥusaynīya al-miṣrìya, 1907, III, 31; Abū Šāma, Rawdatayn, I, 335; Sibṭ b. al-Ğawzì, Mirōât, I, $228-29$.

21) al-Aynī: 'Iqd al-ğumān fī ta'rīh ahl az-zamān, 4 Bd., hg. v. Muhammad Aмīn, Kairo: al-Hay’a al-miṣrīya al- ${ }^{\complement a}$ àmma li-l-kitāb, 1987-92, IV, 263-64 zu dem Erdbeben in Ägypten im Jahre 702/1303. Ibn Qāḍi Šuhba: al-Ic $\bar{a} m$ bi-ta’rīh ahl al-istām, 5 Bd., hg. v. 'Adnān DARwīš, Damaskus: Institut Français de Damas, 1977-97; I, 265 zum Erdbeben in Hुurāsān im Jahre 791/1389. 
spirituellen Krisenbewältigung auf. Diese wurden jedoch in einer immer wiederkehrenden geradezu formelhaften Begrifflichkeit ausgedrückt: „Als die Bewohner von Damaskus von dem Erdbeben heimgesucht wurden, erschraken sie vor seiner Gewalt. Sie flüchteten in Furcht um ihr Leben aus ihren Häusern und überdachten Bauten in die Moschee und auf unbebautes Gelände. Als ein weiteres [Erdbeben] kam, wurden die Stadttore geöffnet und die Leute verließen [die Stadt] in Richtung der Gärten und der Wüste. So blieben sie einige Tage in Furcht und Schrecken. Sie sprachen die Formeln „Gepriesen sei Gott“ und „Es gibt keinen Gott außer dem einen Gott“. Sie flehten ihren Schöpfer und Ernährer um Milde und Gnade an. “22 Der Topos „Schrecken - Flucht außerhalb der Stadtmauern Bittgebete" strukturierte immer wieder die Berichte über das Verhalten der Menschen, und spielt somit eine zentrale Rolle im Diskurs der Kontinuität. Ein typisches Charakteristikum dieses Topos war dabei, dass Anrufungen Gottes wie etwa tasbīh, tahlīl und takbīr erwähnt wurden. ${ }^{23}$

Wie eingangs betont konnte der Diskurs der Kontinuität keine Exklusivität beanspruchen, da in anderen Literaturgattungen abweichende Aussagen möglich waren. Wenn solche Beschreibungen vorkamen, so schlugen sie schnell von der Marginalisierung dieser Ereignisse in das andere Extrem um und stellten den Zusammenbruch sämtlicher Werte dar. Der irakische Gelehrte 'Abd al-Lațif al-Baġdādī, zum Beispiel, stellte als Außenseiter in seiner Beschreibung Ägyptens einen solchen Zusammenbruch des Wertesystems in Ägypten dar, das in den Jahren 597 und 598 (1200-1202) von einem Erdbeben sowie einer Hungerkrise und einem Seuchenausbruch heimgesucht wurde. ${ }^{24}$ Er berichtete vom sich ausweitenden Kannibalismus, dem insbesondere Kinder zum Opfer gefallen seien und von der drakonischen Abschreckungsstrafe (Verbrennen bei lebendigem Leibe), die sich seinem Bericht zufolge auch als problematisch erwies, da die verkohlten Leichnahme selbst wieder verspeist würden. ${ }^{25}$ Darüber hinaus beschrieb er, dass Tote nicht mehr beerdigt würden, Pros-

22) Abū Šama, Rawdatayn, I, 334 zum Erdbeben im Jahre 552/1157 in Syrien: „yusabbih̄una wa-yuhallitūna wa-yarğabūna ilā ḩāliqibim wa-rāziqihim fī al-luṭf bihim wa-al- ${ }^{c}$ afw ${ }^{c}$ anhum. "

${ }^{23}$ ) So zum Beispiel zu diesem Erdbeben: Ibn al-Qalānisī, Dayl, 343 (tahlīl,

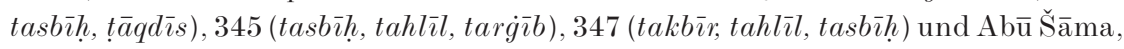

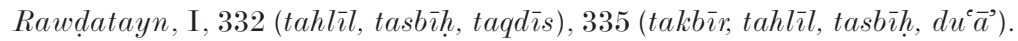

$\left.{ }^{24}\right)$ al-Bag̀dādī: Kitāb al-ifāda wa-al-iétibār fī al-umūr al-mušăhada wa-al-ha-

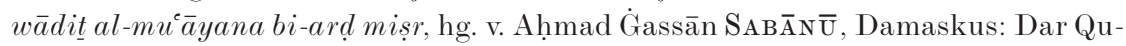
tayba, 1983, 85-105.

${ }^{25)}$ al-Bağdādī, Ifā $d a, 87$. 
titution um sich greife, Muslime von ihren eigenen Familienangehörigen in die Sklaverei verkauft würden und ausufernder Diebstahl, beziehungsweise Vandalismus zunehmend härtere Schutzmaßnahmen erforderten.

Von solch dramatischen Beschreibungen - unabhängig vom Wahrheitsgehalt des Berichtes von al-Bağdādī - war in den Chroniken nur ein leises Echo wahrnehmbar. ${ }^{26}$ Die Autoren tendierten dahin, Abweichungen von gesellschaftlichen Ordnungsvorstellungen während der Krisenzeit nicht zu berichten. Selbst Passagen, die das spirituelle „Krisenmanagement“ der Bevölkerung erwähnten, verwendeten den oben dargestellten Topos „Schrecken - Flucht außerhalb der Stadtmauern - Bittgebete“. Die Marginalisierung der spirituellen und sozialen Veränderungen, die die Katastrophe verursachte, weist auf den primär normativen - und nicht deskriptiven - Charakter von Erdbebenberichten in Chroniken und deren Einbettung in den Diskurs der Kontinuität hin. Anstelle von umfangreicheren Beschreibungen der Folgen der jeweiligen Erdbeben griffen die Autoren vielmehr auf standardisierte Textbausteine zurück.

\section{Erdbebenabhandlungen}

Diese normative Bedeutungsebene der Chroniken lässt sich erschließen, wenn ein weiteres Genre, das der bereits erwähnten „Erdbebenabhandlungen", einbezogen wird. Damit sind Abhandlungen gemeint, die kosmologische Erklärungen von Erdbeben, Reflexionen zu ihrer Bedeutung und spirituelle Handlungsanweisungen beinhalteten. $\mathrm{Zu}$ trennen davon sind historische Abhandlungen, die in erster Linie aus Berichten zu einzelnen Erdbeben bestanden, ${ }^{27}$ und Schriften, die Erdbeben über-

${ }^{26)}$ Abū Šāma, Rawḍatayn, IV, 485 zitierte al-Kātib al-Iṣfahānī, der die katastrophale Lage nur in sehr allgemeinen Tönen beschrieb. Abū Šāma, Dayl, 19, Ibn al-Ațīr, Kāmil, XII, 170 und Ibn Wāșil, Mufarriğ, III, 127 erwähnten zumindest den Kannibalismus, gingen aber auf andere Folgen der Katastrophe nicht ein.

${ }^{27}$ ) Die Abgrenzung ist selbstverständlich nicht immer eindeutig. Eine titellose Abhandlung, die wahrscheinlich von Muṣtafā b. Ibrāhīm al-Alawānī (st. $1193 / 1779$ ) verfasst wurde (hg. v. M. A. TAHER: Textes d'historiens damascènes sur les tremblements de terre, in: Bulletin d'Etudes Orientales 27 (1974), 51-108, hier 77-94), weist eine kurze kosmologische Einleitung und kurze Kommentare zu der Bedeutung von Erdbeben auf. Da der Hauptteil jedoch die Zerstörung von Bauwerken in Damaskus durch das Erdbeben im Jahre 1173/1759 behandelt, ist sie eher dem Genre der Chroniken zuzurechnen. Umgekehrt verhält es sich mit der

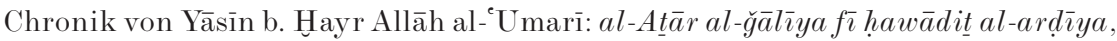
MS British Library Or 6300, die einen so starken Schwerpunkt auf Erdbeben legt, 
wiegend aus naturkundlicher Perspektive betrachteten. Solche Abhandlungen wurden zu den drei verheerenden Katastrophenarten verfasst, die den Nahen Osten in der vormodernen Periode trafen: Seuchen, ${ }^{28}$ Erdbeben und Hungersnöte. ${ }^{29}$ Die Erdbebenabhandlungen ähnelten in ihrer Funktion den entsprechenden Abschnitten in Chroniken. Auch hier dominierte eine stark typologisierte Beschreibung der Reaktionen auf das Erdbeben, der materiellen Schäden und der Opferzahlen. Trotz dieser vergleichbaren Funktion erlauben die Abhandlungen jedoch bereits aufgrund ihres größeren Umfangs ein wesentlich besseres Verständnis der diskursiven Strategien in Bezug auf Erdbeben.

Die Autoren dieser Abhandlungen waren, ebenso wie die Autoren der zuvor genannten Chroniken, in erster Linie Gelehrte, die sich mit den religiösen Wissensgebieten im engeren Sinne (zum Beispiel Tradition, Qur’ān-Rezitation, Qur’ān-Kommentar) beschäftigen. Dieser Schwerpunkt stand im Gegensatz zu den unterschiedlichen Hintergründen einer zweiten Kategorie von Autoren, bei denen diese Wissensgebiete eine geringere Rolle spielten und deren Texte nicht dem Diskurs der Kontinuität zugeordnet werden können. Neben den im Folgenden erwähnten Autoren, die naturkundliche Erklärungen betonten, sind hier auch die Verfasser von Anthologien zu nennen, die Erdbeben behandelten. Der syrische „Ritter" und Gelehrte Usāma b. Munqid (st. 584/1188) etwa betrauerte in seinem Werk Kitāb al-manāzil wa-ad-diyār seine Verwandten, die bei der vollständigen Zerstörung der Burg der Banū Munqid im mittelsyrischen Šayzar beim Erdbeben des Jahres 552/1157 umgekommen waren. ${ }^{30}$ Die in den Erdbebenabhandlungen behandelten Themen spielen in diesem Werk nur eine marginale Rolle. Ebenso stammte der obige „Kannibalismus“-Bericht mit seiner deutlich abweichenden Intention

dass sie einer Abhandlung zu diesem Thema nahe kommt (so z. B. 49b-50a mit einem Bericht zu dem Erdbeben von 552/1157).

$\left.{ }^{28}\right)$ M. W. Dols: The Black Death in the Middle East, Princeton 1977, 320-35 enthält eine Übersicht über Pestabhandlungen, und L. I. ConraD: Arabic Plague Chronicles and Treatises: Social and Historical Factors in the Formation of a Literary Genre, in: Studia Islamica 54 (1981), 51-93 diskutiert die Entstehung dieses Genres.

$\left.{ }^{29}\right)$ Die bekannteste Abhandlung zu diesem Thema ist al-Maqrīzì: Ig்ătat alumma bi-kašf al-gumma, hg. v. Muḥammad M. AZ-ZIYĀDA/Ğamāl ad-Dīn A ̌̌-

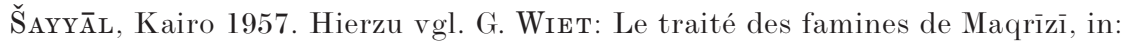
Journal of the Economic and Social History of the Orient 5 (1962), 1-90 und A. ALLOUCHE: Mamluk Economics: A Study and Translation of al-Maqrīzì's Ighāthah, Salt Lake City 1994.

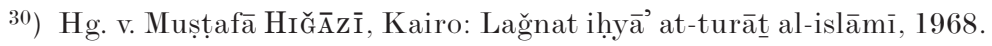


von einem Autor, der sich verstärkt den naturkundlichen Wissensgebieten widmete. Berichte von einer dritten Kategorie von Autoren, jenen die nicht den gelehrten Kreisen im engeren Sinne angehörten, entstanden erst während der osmanischen Periode, so etwa das Tagebuch eines Barbiers aus Damaskus, welches Einträge zu Erdbeben enthielt. ${ }^{31}$ Berichte von Autoren der zweiten und dritten Kategorie waren jedoch quantitativ marginal im Vergleich zur Vielzahl an standardisierten Darstellungen in den Chroniken und den Erdbebenabhandlungen, die anscheinend sehr viel eher dem Geschmack der Literati entsprachen.

Das Genre der arabischsprachigen Erdbebenabhandlungen hatte seinen Ursprung wohl im späten 5./11. Jahrhundert. Zu den bekannten Titeln dieses Genres gehörten al-Ḩațīb al-Bağdādī (st. 463/1071): Das Buch der Erdbeben ${ }^{32}$ (nicht überliefert), 'Alī b. Abī Bakr al-Arašānī (st. 557/1162): Die Erdbeben und die Zeichen [des Jüngsten Tages] ${ }^{33}$ (nicht überliefert), Ibn Asākir (st. 571/1176): Das Buch der Erdbeben/Das Buch der Warnung vor dem Eintreten von Erdbeben ${ }^{34}$ (nicht überliefert), Šăfi ${ }^{e}$ b. 'Abd az-Zāhir (st. ?): Die augenscheinlichen Hinweise auf die Ereignisse und die Erdbeben, ${ }^{35}$ as-Suyūṭī (st. 911/1505): Die Beschreibung des Erdbebens ohne Getöse, ${ }^{36}$ Ibn al-Ğazzār (st. später 10./16. Jhd.): Die Befestigung der Heimstätten gegen das Schrecken der Erdbeben ${ }^{37}$ und Hāamid b. 'Alī al-' Imādī (st. 1171/1758): Das Aussprechen der Formel „Es gibt keine Stärke und keine Macht außer durch Gott "bei Erdbeben. ${ }^{38}$

$\left.{ }^{31}\right)$ al-Budayrī: Kitāb ḥawādit Dimašq al-yawmīya, 98-101; die Erdbeben betreffenden Passagen wurden hg. v. M. A. TAHe R (1974): Textes d'historiens damascènes sur les tremblements de terre, in: Bulletin d'Etudes Orientales 27, 51-108, hier 95-101.

32) Kitāb az-zalāzil (zitiert in as-Suyūṭī, Kašf, 133).

${ }^{33}$ ) az-Zalāzil wa-al-ašrāt (hierzu siehe Ț̣̂̄HIR, Einleitung zu Ibn al-Ğazzār, Tahṣin, 134).

34) Kitāb az-zalāzil (zitiert in as-Suyūṭī, Kašf, 133, 170; Ibn al-Ǧazzār, Tahṣīn,

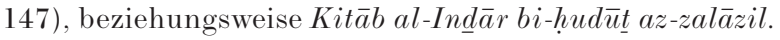

35) Mā z̧ahara min ad-dalāil fī al-hawādiț wa-az-zalāzil. Der Autor verfasste diese Abhandlung in Form einer maqāma anlässlich des Erdbebens in Ägypten und Syrien im Jahre 702/1303 (zitiert in as-Suyūṭī, Kašf, 202-205).

$\left.{ }^{36}\right)$ Kašf aș-ṣalșala an wașf az-zalzala.

37) Tahșīn al-manāzil min hawl az-zalāzil.

${ }^{38)}$ al-Hawqala fī az-zalzala. Aus Verweisen ist deutlich, dass eine Anzahl weiterer Abhandlungen verfasst wurde. ${ }^{c}$ Umar b. al-Wardī (st. 749/1349) etwa erwähnte, dass er eine Abhandlung zu diesem Thema aufgrund des Erdbebens von 744/1355, das Anatolien und Nordsyrien traf, verfasst hätte (Ibn al-Wardī: Ta’rīh Ibn al-Ward̄̄, 2 Bd., Beirut: Dār al-kutub al-íilmīya, 1996, II, 327-28). 
Von den vier überlieferten Erdbebenabhandlungen sind drei von einer ausreichenden Länge, um sie weitergehend zu analysieren. ${ }^{39}$ Auf as-Suyūtīis Die Beschreibung des Erdbebens ohne Getöse ${ }^{40}$ folgte der wenig bekannte ägyptische Gelehrte Ibn al-Ğazzār, der anlässlich eines Erdbebens in Unterägypten im Jahre 984/1576 eine an as-Suyūṭi angelehnte Abhandlung unter dem Titel Die Befestigung der Heimstätten gegen das Schrecken der Erdbeben veröffentlichte. ${ }^{41}$ Etwa 150 Jahre später betitelte der Damaszener Muftī al- ${ }^{\complement}$ Imādī nach einem Erdbeben im Jahre 1148/ 1735 eine Abhandlung zum gleichen Thema mit Das Aussprechen der Formel „Es gibt keine Stärke und keine Macht außer durch Gott" bei Erdbeben ${ }^{42}$ Aus den Zitaten und Titeln der anderen Erdbebenabhandlungen, deren Gesamttexte nicht überliefert sind, kann angenommen werden, dass sie hinsichtlich des Aufbaus im Wesentlichen den im Folgenden diskutierten Texten glichen.

Die genannten Erdbebenabhandlungen weisen alle einen recht ähnlichen Aufbau auf. Ihr Inhalt kann in vier Hauptkategorien unterteilt werden, denen die Autoren allerdings unterschiedliche Bedeutung zumaBen: Einzelberichte über Erdbeben von der Schöpfung bis in die Gegenwart, kosmologische Erklärungen von Erdbeben, Diskussionen zur Bedeutung von Erdbeben und Anweisungen zum richtigen religiösen Verhalten beim Eintritt einer solchen Katastrophe. Andere Themen ${ }^{43}$ um-

${ }^{39}$ ) Ibn `Abd az-Ẓāhir, Dalä’il umfasst lediglich 45 Zeilen.

$\left.{ }^{40}\right)$ Die Popularität dieses Werks ist anhand der etwa 20 überlieferten Manuskripten ersichtlich. Neben der hier verwendeten Edition von 1987, wurde das Werk auch von ${ }^{\complement} A b d$ al-Lațif AS-SA ${ }^{\complement} D \bar{A} N \bar{I}$, Fès 1971, herausgegeben und von S. NEJJAR: Traité du tremblement de terre, Rabat: Centre universitaire de la recherche scientifique, 1973-74 teilweise übersetzt. Die Übersetzungen von A. SPREnger, in: Journal of the Asiatic Society of Bengal, 12 (1843), 741-49 und N. N. АмвrASEYS: On the Seismicity of Southwest Asia: Data from a XV Century Arabic Manuscript, in: Revue pour l'Etude des Calamités 37 (1961), 18-30 sind ebenfalls unvollständig. Die ausführlichste Studie zu as-Suyūṭis Werk ist J. F. CLÉ ment : Jalāl al-Dīn Suyūṭī, séismosophe, in: IVèmes rencontres internationales d'archéologie et d'histoire d'Antibes: Tremblements de terre. Histoire et archéologie: 2, 3, 4 Novembre 1983, Valbonne 1984, 253-87.

$\left.{ }^{41}\right)$ Die hier verwendete Edition beruht auf den beiden bekannten noch existierenden Manuskripten.

${ }^{42}$ ) Der Text wurde in einer Sammlung der Abhandlungen des Autors überliefert.

$\left.{ }^{43}\right)$ as-Suyūṭī, Kašf, 211-12; Ibn al-Ğazzār, Tahṣīn, 142 (Z. 1-13), 147 (Z. 17)148 (Z. 8), 154 (Z. 21 )-155 (Z. 7), 155 (Z. 20)-156 (Z. 7); al- 'Imādì, Hawqala, 61 (Z. 1-2, 17-18), 65 (Z. 20-21). 
fassten einerseits die einleitenden und abschließenden Segensformeln und andererseits für den jeweiligen Autor singuläre Abschnitte wie zum Beispiel bei Ibn al-Ğazzār die Bedeutung des Todes von 'Alī und seinen Söhnen Hasan und Husayn, bei as-Suyūṭi Weisheiten, Sprichwörter und Gedichte zu Erdbeben und bei al- ${ }^{e}$ Imādī Überlegungen zur Vokalisierung des Begriffes „Erdbeben“ (zilzala/zalzala). Sie nahmen bei as-Suyūṭi mit unter zwei Prozent des Gesamttextes ebenso wie bei al- ${ }^{e}$ Imādī mit unter vier Prozent eine marginale Stellung ein. Der relativ breite Raum, den diese Kategorie bei Ibn al-Ğazzār mit fünfzehn Prozent innehatte, erklärt sich auch durch die umfangreichen Segensformeln, die bereits die Hälfte dieser Passagen ausmachten.

Der früheste Autor der hier untersuchten Erdbebenabhandlungen, as-Suȳuțī, hatte den ausführlichsten Text verfasst, was auch darauf zurückzuführen ist, dass as-Suyūṭīs Text teilweise paradigmatischen Wert hatte. So ist die abnehmende Länge der kosmologischen Abschnitte von

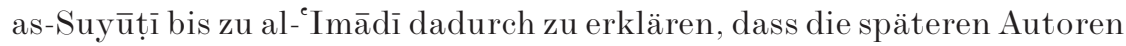
as-Suyūṭis Darlegung akzeptierten und nur leicht modifizierten. Dabei übernahmen sie seine Kernaussagen und ließen Teile des umfangreichen Belegmaterials weg.

\section{Thematische Schwerpunkte in Erdbebenabhandlungen}

\begin{tabular}{|l|c|c|c|c|c|}
\hline & Kosmologie & $\begin{array}{l}\text { Einzel- } \\
\text { berichte }\end{array}$ & $\begin{array}{l}\text { Bedeutung } \\
\text { von } \\
\text { Erdbeben }\end{array}$ & $\begin{array}{l}\text { Verhaltens- } \\
\text { anweisungen }\end{array}$ & Andere \\
\hline $\begin{array}{l}\text { As-Suyūṭi } \\
(889)^{44}\end{array}$ & 47 & 592 & 121 & 112 & 17 \\
\hline $\begin{array}{l}\text { Ibn al-Ğazzār } \\
(333)\end{array}$ & 36 & 54 & 122 & 70 & 51 \\
\hline $\begin{array}{l}\text { al- }{ }^{c} \text { Imādī } \\
(123)\end{array}$ & 26 & 4 & 40 & 49 & 4 \\
\hline
\end{tabular}

In der Einleitung zu seiner Abhandlung führte Ibn al-Ğazzār Aussagen seiner Zeitgenossen an, die ihn zur Niederschrift des Textes bewegt hätten. Hierbei warf er zwei zentrale Themen auf, die beispielhaft die Intentionen zeigen, die die Autoren von Erdbebenabhandlungen bei der

${ }^{44)}$ Zahlenangaben beziehen sich auf die Zeilenanzahl in den hier verwendeten Editionen. 
Abfassung ihrer Texte verfolgten. Zunächst zitierte Ibn al-Ğazzār verschiedene Aussagen hinsichtlich der Frage, was die Ursachen für Erdbeben seien. Dies berührte einerseits kosmologische Vorstellungen und stand andererseits mit der Bedeutung von Erdbeben als Ermahnung und Strafe im Zusammenhang. Implizit mitgedacht war dabei, ob sich diese Katastrophe verhindern ließe, wie es auch in den Worten eines anonymen Fragers bei Ibn al-Ğazzār ausgedrückt wurde: „Gibt es für diesen Durst Wasser? Gibt es für diese Krankheit eine Heilung?" Die zweite zentrale Frage, die in den von Ibn al-Ğazzār zitierten Aussagen deutlich wurde, war die, wie auf diese Katastrophe nach ihrem Eintritt zu reagieren sei. Hier rückt das Thema der Verhaltensanweisungen in den Mittelpunkt, die die Autoren ebenfalls mit einer gewissen Ausführlichkeit diskutierten. Die Autoren der Erdbebenabhandlungen beantworteten diese beiden Fragen nach der Ursache von Erdbeben und der richtigen Reaktion hierauf in ihren Texten anhand der vier Kategorien „Kosmologie“, „Einzelberichte“, „Bedeutung von Erdbeben“ und „Verhaltensanweisungen“.

Die Autoren waren zunächst bestrebt, in dem kosmologischen Abschnitt konkurrierende, d. h. in erster Linie naturkundliche, Erklärungen von Erdbeben zu widerlegen. Daraufhin brachten sie die von ihnen bevorzugten Erklärungen vor, laut derer Erdbeben als göttliche Zeichen zu verstehen seien. Hierfür wählten sie unterschiedliche narrative Strategien, ohne aber signifikante inhaltliche Unterschiede an den Tag zu legen. AsSuyūṭi brachte seine Argumentation im Abschnitt zu den Einzelberichten implizit vor. Dagegen führten Ibn al-Ğazzār und al- Imādì die Diskussion im Abschnitt zur Bedeutung von Erdbeben, wo sie ihre Argumente explizit ausdrückten. Nachdem die Autoren somit die Gründe für das Auftreten von Erdbeben eingeordnet hatten, gingen sie im Abschnitt zu Verhaltensanweisungen darauf ein, wie auf Erdbeben richtig zu reagieren sei. Ziel dieser vier Abschnitte war es, im Rahmen des Diskurses der Kontinuität dem Leser angesichts der Schrecken dieser Katastrophen Gewissheit und Versicherung zu geben.

\section{Erdbebenabhandlungen: Kosmologie}

Die Verfasser der Erdbebenabhandlungen zielten in den kosmologischen Abschnitten insbesondere darauf ab, Erklärungen, die auf der pneumatischen Erdbebentheorie der Antike basierten, zu widerlegen. ${ }^{45}$

$\left.{ }^{45}\right) \mathrm{Zu}$ den verschiedenen antiken Erdbebentheorien siehe WALDHE R R, Rezeption, 47-102. 
Erdbeben waren laut diesen Erklärungen eine Folge von Gasansammlungen unter der Erdoberfläche, die durch die Wärme der Sonne entstanden. Da diese Gase weder kondensieren noch entweichen können, führt der ansteigende Druck zu Erschütterungen auf der Erdoberfläche. Diese Erklärung war in jenen Gelehrtenkreisen populär, die sich auch dem Studium der antiken Wissenschaften widmeten. Zu ihnen gehörten Autoren wie Ibn Sīnā in seinem Werk Die Rettung, al-Qazwīnī in seiner Kosmographie und al-Abhārī (st. 663/1264) in der philosophischen Abhandlung Führung der Weisheit. Deutlich wird die Rezeption dieser Erklärung auch im Titel von al-Kindīs Abhandlung zum Wissen über die Winde im Inneren der Erde, die viele Erdbeben und Verfinsterungen hervorrufen. ${ }^{46}$

Neben diesem Ansatz fanden sich weitere Erklärungen, die für die Autoren der Abhandlungen besorgniserregend sein mussten. So kann es durchaus als Echo des pneumatischen Erklärungsansatzes verstanden werden, wenn Chronisten das Vorkommen von Erdbeben auf oberirdische Stürme zurückführten. ${ }^{47}$ Ibn al-Ğazzār zählte in seiner Abhandlung fünf verschiedene Erklärungsansätze für das Erdbeben im Jahre 984/1576 auf, die zu seiner Zeit in Kairo kursierten. Neben der pneumatischen Erdbebentheorie nannte er die moralische Schwäche der ägyptischen Regionen, die Vorstellung, dass die Welt von einem Stier getragen wird, der Erdbeben hervorrufen kann, die Sündhaftigkeit der Menschheit und verwies schließlich auf den mythischen arabischen Stamm ${ }^{\circledR} \bar{A} d$, den Gott durch Naturkatastrophen ausgelöscht hatte und dessen Sünden fortwirkten. ${ }^{48}$

Ibn al-Ğazzār kritisierte nach dieser Aufzählung zunächst in aller Deutlichkeit die Anhänger der pneumatischen Erdbebentheorie, deren Erklärung die anderen beiden Abhandlungen ebenfalls explizit verwar-

$\left.{ }^{46}\right)$ Ibn Sīnā: Kitāb an-Nağāt, Kairo: Maṭba ât as-saēada, 1331/1912-13,

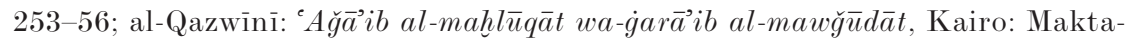
bat M. Mușțafā Fahmī, 141; al-Abhārī, Mufaḍdal b. ${ }^{e}$ Umar: Hidāyat al-ḥikma, zitiert in al- ${ }^{\mathrm{C}} \mathrm{Ima \overline {d }} \mathbf{i}$, Hawqala, 63; Ya ${ }^{\mathrm{c}} \mathrm{q} \overline{\mathrm{u}} \mathrm{b}$ b. Ishạq al-Kindī (st. Mitte 3./9. Jhd.):

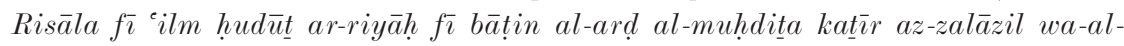
hus usf, zitiert in Ibn an-Nadīm: Kitāb al-fihrist, hg. v. G. FLÜGEL, Leipzig 1871, 261.

$\left.{ }^{47}\right)$ So zum Beispiel al-Ğawharī/Ibn aṣ-Șayrafĩ: Nuzhat an-nufūs wa-al-abdān fī tawārīh az-zamān, 4 Bd., hg. v. Ḥasan ḤABAšs̄ , Kairo: Maṭba ât Dār al-kutub, 1970-94, I, 173-74 zum Erdbeben in Hurāsān im Jahre 791/1389: „Ein starker Stürm wütete in Nīsābūr, von dessen gewaltigen Böen die Erde bebte“.

48) Ibn al-Ğazzār, Tahṣīn, 142-43. 
fen. ${ }^{49}$ Gegen solche Erklärungen setzten die Autoren mittels qur'ānischer Zitate und prophetischen hadīten die kosmologische Vorstellung, dass die Erde von dem Berg Qāf umgeben sei. ${ }^{50}$ Dieser Berg wiederum sei mit dem Felsen verbunden, auf dem die Erde ruhe. Gott führe Erschütterungen auf der Erde herbei, indem er dem Berg Qāf befähle, sich zu bewegen. Durch die zahlreichen Verbindungen zwischen Erde und Felsen würde somit genau der Teil der Erde erschüttert, der von dem Erdbeben getroffen werden solle. Durch diese Beschreibung versuchten die Autoren zu erklären, wie es kommt, dass bei einem Erdbeben gewisse Regionen betroffen waren, die Nachbarregionen aber ausgespart blieben. ${ }^{51}$

Die Abhandlungen führten diese kosmologische Vorstellung teilweise aus und nahmen Bezug auf den von Ibn al-Ğazzār ebenfalls aufgezählten mythischen Erklärungsansatz, dass die Welt von einem Stier getragen würde. Erdbeben würden dadurch verursacht, dass der Stier den Felsen nur auf einem seiner Hörner trage und gelegentlich das tragende Horn wechsle. ${ }^{52}$ Ibn al-Ğazzār machte deutlich, dass er diese Vorstellung für Geschwätz hielt, für „Gerede des Richters, der aus dem gemeinen Volk und von den Niederen kommt. " ${ }^{53}$ Allerdings räumten die Autoren der Abhandlungen einer weiter entwickelten Version dieser Vorstellung durchaus einen umfangreichen Platz ein, indem sie sie mit der Qāf-Kosmologie verbanden. Demnach ruhe der Felsen auf einem Stier, der wiederum auf einem Wal stehe. Erdbeben entstünden hiernach auf göttliche Anweisungen durch Bewegungen des Berges Qāf oder des Wals.

Für Ibn al-Ğazzār, wie auch für die anderen Autoren, war in erster Linie die Quintessenz der verbleibenden Erklärungsansätze relevant. Erdbeben waren eine göttliche Mahnung oder Strafe aufgrund der Vielzahl von Sünden, die die Menschen begangen hatten. Durch den Verweis

${ }^{49}$ ) Dies ist auch sichtbar im Manuskript Berlin We. 1174 (Ahlwardt 6054) mit dem Titel Erdbeben und die Meinungsunterschiede zwischen den Gelehrten hinsichtlich der Frage wie man die Bewegung der Erde festlegen kann (al-qawl 'alā az-

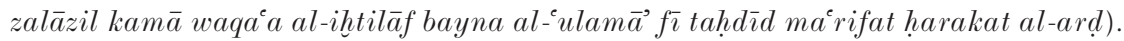
Eine ähnliche Diskussion zwischen Anhängern zweier solcher Richtungen existierte auch im spätrömischen Reiche, siehe MeIE R, Perceptions, 182.

$\left.{ }^{50}\right)$ Die kosmologischen Abschnitte finden sich in: as-Suyūtī, Kašf, 133-36; Ibn al-Ğazzār, Tahṣìn, 143 (Z. 11-14), 146 (Z. 12)-157 (Z 16); al-'Imādī, Hawqala, 63 (Z. 22)-64 (Z. 19).

51) as-Suyūṭī, Kǎ́f, 133; Ibn al-Ğazzār, Tahṣīn, 147.

${ }^{52}$ ) Dies mag ein Echo des Stiermotivs der antiken mythologischen Tradition, insbesondere Kretas, sein, das auch in Verbindung mit seismischen Aktivitäten stand. Zu dieser Tradition siehe WALDher R, Rezeption, 221-22.

53) Ibn al-Ǧazzār, Tahṣ̂̄n, 142. 
auf den Stamm ‘ $\bar{A} d$ wurde dem Leser die aus Qur’ān und qiṣaṣ al-anbiy $\bar{a}^{\prime}$ bekannte Legende der Vernichtung eines sündhaften Stammes, der Gottes Gesandtem kein Gehör geschenkt hatte, in Erinnerung gerufen. Auch die erste Erklärung, die Schwäche Ägyptens, zielt auf den gleichen Punkt ab, denn „Schwäche“ setzte der Autor mit der „Vielzahl an Unzucht und Ehebruch" in der ägyptischen Gesellschaft gleich. Ziel der kosmologischen Abschnitte war somit in allen drei Abhandlungen die Widerlegung konkurrierender Erklärungsmuster, um diskursiven Raum für die eigenen Reflexionen zur Bedeutung und damit zu den - zumindest aus Sicht dieser Autoren - eigentlichen Gründen für Erdbeben zu schaffen.

\section{Erdbebenabhandlungen: Einzelberichte}

As-Suyūṭī zog es vor, seine Überlegungen zur Bedeutung von Erdbeben im Rahmen der Kategorie „Einzelberichte“ einzubringen. Dies ist bereits anhand der Länge dieses Abschnitts ersichtlich, der rund zwei Drittel seiner Abhandlung ausmachte. Dagegen spielten Einzelberichte bei Ibn al-Ğazzār und bei al-'Imādì lediglich eine untergeordnete oder marginale Rolle. ${ }^{54}$ As-Suyūṭi schrieb seiner ausführlichen Liste der Erdbeben durch einen theologischen und heilsgeschichtlichen Rahmen eine zentrale Position im Text zu. So leitete er die Liste mit sieben Erdbeben ein, die von Abraham über Šu ayb und Moses bis zu den Zeichen reichten, die die Prophetenschaft Muḥammads ankündigten. Hiermit lieferte er den interpretatorischen Hintergrund für die folgenden Einzelberichte: Erdbeben kündigten bedeutsame Einschnitte in der Heilsgeschichte an (Prüfung Abrahams, Ankündigung der Prophetenschaft Muhammads, Geburt Muhammads). Weiterhin bestraften sie diejenigen, die sich gegen Gott und seine Gesandten wandten, das heißt nicht nur die Gegner Šcuaybs, sondern auch die Widersacher Moses, die das goldene Kalb verehrten, sowie die „Gefährten des Elefanten“, die im Geburtsjahr des Propheten versuchten, Mekka zu erstürmen, und auch der sāsānidische Herrscher als der zukünftige Gegner der Muslime, dessen Palast bei der Geburt des Propheten beschädigt wurde. ${ }^{55}$

Durch das Erdbeben, das den Palast des sāsānidischen Herrschers getroffen hatte, wendete as-Suyūṭi den Blick bereits auf die islamische Periode. Aber auch hier ging er nicht unmittelbar zu den Einzelberichten

$\left.{ }^{54}\right)$ as-Suyūṭì, Kašf, 157-210, 213; Ibn al-Ğazzār, Tahṣ̄nn, 142 (Z. 14-18), 151 (Z. 22)-154 (Z. 10); al- ${ }^{\mathrm{e}}$ Imādī, Hawqala, 61 (Z. 3-4, 7-8).

55 ) as-Suy ūṭì, Kašf, 157-64. 
über, sondern führte zunächst erneut den theologischen Rahmen der Erdbebenberichte aus. Er betonte mittels eines hadīt, dass Erdbeben zur Reue aufforderten und führte mittels eines - ungewöhnlicherweise nicht datierten - Erdbebenberichts aus, dass Erdbeben die Sünder träfen, hier diejenigen, die Zinsen nehmen. Der Autor stellte die Kontinuität heilsgeschichtlicher Aspekte durch hadīte sicher, die den Propheten mit den „rechtgeleiteten“ Kalifen Abū Bakr, 'Umar, 'Uțmān und 'Alī während eines Erdbebens zeigten. Muhammad forderte die Erde auf, ruhig zu sein, denn auf ihr befänden sich ein Prophet, ein Aufrichtiger (siddīq) und ein Märtyrer. ${ }^{56}$ Zwei Berichte zu ${ }^{c}$ Umar und ${ }^{c} A l i ̄$, die beide Erdbeben beendeten, indem sie auf die Erde schlugen, schlossen die Überleitung in die islamische Periode ab. ${ }^{57}$

Von dieser Stelle an wandelt sich der Text erheblich, da die folgende umfangreiche Liste einzelner Erdbeben überwiegend aus knappen Berichten besteht. Dennoch führte as-Suyūṭi durchaus noch Interpretationen zu Erdbeben an. Dies geschah meist in der Form von Poesie, Sendschreiben oder kurzen Anekdoten. So berichtete er, dass in Aleppo nach einem Erdbeben im Jahre 242/856 ein weißer Vogel erschien, der zur Gottesfurcht aufrief und vierzig Mal das Wort „Gott“ wiederholte. ${ }^{58}$ Durch die zentrale Funktion des weißen Vogels spielte er auf die Überlieferung zu den „Gefährten des Elefanten“ an, zu denen Gott nach dem Erdbeben, gemäß der von as-Suyūṭi zuvor erwähnten Version, ebenfalls weiße Vögel gesandt hatte.

Neben dieser Interpretation von Erdbeben als Strafe, beziehungsweise Aufruf zur Buße, nahm der Autor auch auf heilsgeschichtliche Aspekte Bezug. So berichtete er, dass sich der ayyūbidische Herrscher Șalāḥ ad-Dīn während des großen syrischen Erdbebens des Jahres 552/1157 in Hamā aufgehalten hatte. Sämtliche Häuser der Stadt mit Ausnahme des Hauses, in dem Șalāḥ ad-Dīn verweilte, wurden zerstört. ${ }^{59}$ Dieser Bericht muss im Zusammenhang mit der Glorifizierung von Șalāḥ ad-Dīn

$\left.{ }^{56}\right)$ Dieses hadīt findet sich ohne die Erwähnung Alīs zum Beispiel in at-Tirmidīi: al-Ğāmic aṣ-ṣahīh, 2 Bd., Vaduz/Kairo: Thesaurus Islamic Foundation, 2000, II, 944 (al-Manāqib, Bāb 19, Nr. 4062); Abū Dāwūd: Kitāb as-Sunan, 2 Bd., Vaduz/Kairo: Thesaurus Islamic Foundation, 2000, II, 782 (as-Sunna, Bāb 9, Nr. 4653); al-Buhārī: Șah̄h al-Buhārē, 3 Bd., Vaduz/Kairo: Thesaurus Islamic Foundation, 2000, II, 724, 726 und 729-30 (Faḍāil aṣ-șaḥāba: Bāb 6, Nr. 3719,

Bāb 7, Nr. 3730 und Bāb 8, Nr. 3746).

${ }^{57)}$ as-Suyūṭi , Kašf, 165-67.

${ }^{58)}$ Ibid., 162.

${ }^{59)}$ Ibid., 191-92. 
nach dessen Tod gesehen werden. Teile der zeitgenössischen Chronistik konstituierten ihn, häufig gemeinsam mit seinem zangīdischen Vorgänger Nūr ad-Dīn, als denjenigen, der die Goldene Frühzeit der umma wieder errichtet hatte und in unmittelbarer Nachfolgerschaft der rechtgeleiteten Kalifen stand. ${ }^{60}$ As-Suyūṭi zog mit seinem Bericht eine entsprechende Verbindungslinie zwischen Șalāḥ ad-Dīn und der Frühzeit. Denn ebenso wie der Prophet Muhammad die Erde aufgefordert hatte, ruhig zu sein, als er sich in Gesellschaft der (späteren) vier „rechtgeleiteten“ Kalifen befand, ruhte die Erde während des Erdbebens in Hamā nun unter den Füßen von Șalāh ad-Dīn. Diese Bedeutungszuschreibung tritt umso stärker hervor, da as-Suyūṭi an keiner Stelle seines Textes eine vergleichbare Anekdote in Bezug auf einen anderen Herrscher berichtete.

Die interpretatorische Klammer der Einzelberichte wurde geschlossen, indem dasjenige hadīt die Liste - und mit ihr die Abhandlung - beendet, das beschreibt wie ein Erdbeben das Kommen des apokalyptischen Wesens (ad-Dağğāl) begleiten wird. ${ }^{61}$ Mittels der dargestellten erzählerischen Mittel verstand es as-Suyūṭi also, seine Liste von Erdbebenberichten in den Gesamtrahmen seiner Abhandlung zu integrieren. Diese enge Verbindung zwischen as-Suyūțis Gesamtrahmen und den Einzelberichten macht aber deutlich, dass die Letzteren selbst in ihrer kursorischen Form in erster Linie nicht faktische Berichte waren. Vielmehr stellten sie wichtige Elemente des Diskurses der Kontinuität dar, da sie die Bedeutung von Erdbeben festschrieben. Die Entscheidung der Übersetzer dieses Werkes, ${ }^{62}$ die „,nicht-faktischen“ Abschnitte und somit einen großen Teil des interpretatorischen Rahmens auszulassen, verleiht dem französischen Text eine scheinbare Faktizität, die vom Autor nicht intendiert war.

Die Einzelberichte waren der einzige Abschnitt in as-Suyūṭīs Text, der keine paradigmatische Funktion für seine Nachfolger hatte. Der geringe Umfang dieser Kategorie in den anderen Erdbebenabhandlungen war eine bewusste Entscheidung, wie in der Kritik Ibn al-Ğazzārs an asSuyūṭis Liste der Erdbeben deutlich wird. Ibn al-Ğazzār argumentierte, dass es ausreiche, einige Beispiele zu nennen, da dies eine „vollständige Ermahnung für den Wissenden sei."63 Die historischen Einzelberichte verdeutlichten lediglich die Ausführungen der anderen Abschnitte der

${ }^{60}$ ) Hierzu vgl. K. Hirschler: Medieval Arabic Historiography: Authors as Actors, London 2006.

${ }^{61)}$ as-Suyūṭī, Kašf, 213.

62) NeJJar, Traité.

63) Ibn al-Ğazzār, Tahṣīn, 154. 
Abhandlung und besäßen keinen eigenen Wert. Diese Sichtweise zeigt sich noch deutlicher in al- ${ }^{e}$ Imādīs Abhandlung, in der die beiden einzigen Einzelberichte zu Erdbeben sich auf eines zu seinen Lebzeiten und eines zu Zeiten seines Lehrers 'Abd al-Ġanī an-Nābulusī (st. 1143/1731) bezogen und insgesamt weniger als vier Prozent des Gesamttextes ausmachten. ${ }^{64}$ Dementsprechend wählten diese beiden späteren Autoren eine andere narrative Strategie und zogen es vor, den interpretatorischen Rahmen in der Kategorie „Bedeutung“ explizit in den Vordergrund zu stellen.

\section{Erdbebenabhandlungen: Bedeutung von Erdbeben}

Überlegungen zu der Frage, welche Bedeutung(en) Erdbeben zukämen und wie sie zu interpretieren seien, ${ }^{65}$ stellen bei Ibn al-Ğazzār den längsten Abschnitt dar und sind auch bei al- ${ }^{c}$ Imādī von erheblicher Bedeutung, während sie bei as-Suyūṭi deutlich hinter die Länge der Einzelberichte zurücktreten. Hinsichtlich der Frage nach der Bedeutungsebene gab es für die Autoren drei Optionen: Erdbeben waren das Werk des Teufels, sie waren eine göttliche Strafe für nicht-muslimische Gruppen, oder Gott sandte sie als Botschaft an die Muslime.

Die Annahme, dass Erdbeben durch den Teufel verursacht wurden, nahm keinen größeren Raum in den Abhandlungen ein. Bezeichnenderweise findet sich die ausführlichste Überlegung zu diesem Thema bei allen drei Autoren auch nicht im Abschnitt zur Bedeutung von Erdbeben, sondern jeweils in einem Exkurs innerhalb des kosmologischen Abschnitts. Der Teufel soll dem Wal eingeredet haben, dass es kein mächtigeres und stärkeres Wesen als ihn gäbe, so dass dieser in seinem Hochmut begann, die Erdbeben selbst hervorzurufen. Gott schöpfte daraufhin in seinem Ohr einen kleinen Wal, der durch seine Bewegungen den großen Wal zur Ruhe bringen konnte. Diese Überlegung war inhaltlich singulär für die Abhandlungen und stach dadurch hervor, dass sie im Gegensatz zu allen anderen Passagen in den Abschnitten zur Kosmologie und der Bedeutung von Erdbeben nicht durch den Überlieferungsweg eingeleitet wurde. Aufgrund dieser Tatsache, dass es sich um eine kosmologische Er-

\footnotetext{
${ }^{64)}$ al- ${ }^{e}$ Imādī, Hawqala, 61.

${ }^{65}$ ) as-Suyūṭī, Kašf, 137-47; Ibn al-Ğazzār, Tahṣìn, 142 (Z. 18)-143 (Z. 10), 143 (Z. 15)-146 (Z. 11), 151 (Z. 8-21), 154 (Z. 11-20), 155 (Z. 8-19); al- 'Imādī, Hawqala, 61 (Z. 5-6, 9-17, 18-20), 64 (Z. 20)-65 (Z. 19).
} 
klärung handelte, die sich nicht im traditionellen Rahmen bewegte, blieb sie selbstverständlich anonym (huddițtu). ${ }^{66}$

Konträr zu dieser Interpretation, in der Gott in erster Linie Erdbeben verhinderte, standen die zweite und die dritte Option, die Erdbeben jeweils als göttliche Mitteilung an den Menschen ansahen. Bei einer Betrachtung des früheren Schrifttums wird deutlich, dass Erdbeben durchaus so gesehen wurden, dass Gott sie gegen Gruppen außerhalb der muslimischen Gemeinde richtete, sie also der Bestrafung der Ungläubigen dienten. Von besonderer Bedeutung war dabei die Anrufung Gottes durch Muḥammad, der um göttlichen Beistand gegen seine „polytheistischen" Gegner bat. In al-Buhārīs hadīt-Sammlung findet sich die entsprechende Überlieferung so im ğihād-Abschnitt in einem eigenen Kapitel „Das Bittgebet [der Herabsendung] von Niederlage und Erdbeben gegen die Polytheisten “. ${ }^{67}$ Die Autoren der Erdbebenabhandlungen dagegen zitieren dieses hadīt, bis auf eine Ausnahme bei al- ${ }^{\mathrm{C}} \mathrm{Ima} \overline{\mathrm{d}} \overline{\mathrm{i}},{ }^{68}$ nicht mehr und Erdbeben als Strafe für die nicht-muslimischen Gruppen waren insgesamt von untergeordneter Bedeutung. Es wurde nur noch vereinzelt in der Phrase erwähnt, die Erdbeben ,als Ermahnung für die Gottesfürchtigen, Akt der Barmherzigkeit für die Gläubigen und als Strafe gegen die Ungläubigen " beschrieb. ${ }^{69}$

Den umfangreichsten Platz in den Abhandlungen nahm die dritte Option ein, nämlich die Sichtweise, dass Erdbeben göttliche Zeichen an die Gemeinschaft der Muslime seien. Diese Zeichen wurden einerseits als Sanktionen für abweichende Verhaltensweisen und andererseits als Ankündigung für den Jüngsten Tag angesehen. Letztere Bedeutungsebene war in den Abhandlungen gewiss auch deshalb von gewisser Bedeutung, da die Autoren hier auf den Qur’ān (Sure 99) rekurrierten: „Wenn [dereinst] die Erde von ihrem [gewaltigen] Beben erschüttert wird und ihre Lasten [an Toten] von sich gibt, und der Mensch [der das miterlebt] sagt:

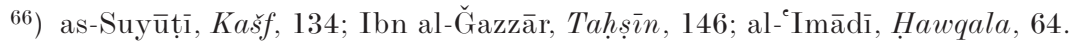

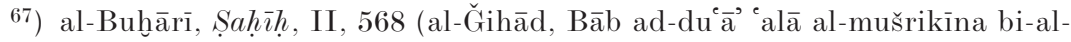
hazìma wa-az-zalzala). Das identische hadīt findet sich weiterhin in al-Buhārī, Șaḥịh, II, 819 (al-Mag̀āzī, Bāb 31, Nr. 4165), III, 1298 (ad-Dáwāt, Bāb 58, Nr. 6465) und III, 1514 (at-Tawhīd, Bāb 34, Nr. 7580); Ibn Māğa: Kitāb as-sunan, Vaduz/Kairo: Thesaurus Islamic Foundation, 2000, 408-409 (al-Ǧihād, Bāb 15, Nr. 2901); at-Tirmidīī, Șaḥ̂̄h, I, 450 (al-Ǧihād, Bāb 8, Nr. 1779); Muslim: al-Ğāamic aș-șah̄h 2 Bd., Vaduz/Kairo: Thesaurus Islamic Foundation, 2000, II, 756 (al-Ğihād wa-as-siyar, Bāb 7, Nr. 4641).

${ }^{68)}$ al- ${ }^{\mathrm{I}} \mathrm{Imā} \mathrm{d} \mathbf{i}$, Hawqala, 61.

$\left.{ }^{69}\right)$ So in as-Suyūṭī, Kašf, 142 und Ibn al-Ğazzār, Tahșīn, 145, 146. 
„Was ist [denn] mit ihr?", an jenem Tag wird sie aussagen, was sie zu berichten hat, da ihr Herr [es] ihr [dann] eingegeben hat. An jenem Tag werden die Menschen [voneinander] getrennt ... hervorkommen, damit ihre [während des Erdenlebens vollbrachten] Werke ihnen [im Einzelnen] gezeigt werden [können]. " Diese Verbindung zwischen Jüngstem Gericht und Erdbeben wurde sowohl im Qur'ān an anderen Stellen als auch im hadit $\underline{t}$ wiederholt betont. ${ }^{70}$

Al-ÁArašānī macht diesen Aspekt im 6./12. Jahrhundert im Titel seiner Erdbebenabhandlung, deren Text uns nicht überliefert ist, besonders deutlich: „Die Erdbeben und die Zeichen [des Jüngsten Tages]“. Die hier untersuchten Abhandlungen zeigten in erster Linie anhand von hadīten, dass nach den ersten Anzeichen des Jüngsten Tages Jahre der Erdbeben folgen werden, ${ }^{71}$ die das Ende der umma ankündigen werden. ${ }^{72}$ So hatte Muhammad die Erde bereits bei einem Erdbeben zurecht gewiesen, da „deine Zeit noch nicht gekommen ist". ${ }^{73}$ As-Suyūṭi unterstrich diese Bedeutungszuschreibung, indem er seine Abhandlung mit einer Prophezeiung Muhammads abschloss, derzufolge ein Erdbeben das Kommen des endzeitlichen ad-Dağğāl begleiten wird. ${ }^{74}$

Am ausführlichsten behandelten die Autoren aber die Vorstellung, dass das Erdbeben ein Mittel göttlicher Kommunikation mit der jeweils zeitgenössischen muslimischen Gemeinschaft sei. Erdbeben seien dabei entweder Aufrufe zur Reue bei abweichenden Verhaltensweisen oder Strafe, wenn von den abweichenden Verhaltensweisen nicht abgelassen würde. Gründe für das Auftreten von Erdbeben seien somit Ehebruch, Konsum von alkoholischen Getränken, Veruntreuung des zakāt oder die

$\left.{ }^{70}\right)$ So zum Beispiel in Sure 22 (1): „Ihr Menschen! Fürchtet euren Herrn! Das Beben der Stunde (des Gerichts) ist etwas Gewaltiges “; 56 (1-5): ,Wenn (dereinst) die Katastrophe (w. die hereinbrechende (Stunde)) (des Gerichts) hereinbricht.... Wenn die Erde hin und her geschüttelt wird und die Berge vollständig zerbröckeln.“; 73 (14): „Am Tag (des Gerichts), da die Erde und die Berge erbeben ..."; 79 (6-7): „Am Tag, da das Beben einsetzt, dem gleich darauf das nächste folgt!“ (Übersetzungen aus R. PARet, Der Koran, Stuttgart ${ }^{7} 1996$. Endzeitliche hadīte, die eine Verbindung zum Erdbeben herstellen finden sich zum Beispiel in at-Tirmidīi, Șah̄in, II, 805-806 (Tafsīr al-Qur’ān, Bā 23, Nr. 3466 und 3467); Ibn Māğa, Sunan, 595-97 (al-Fitan, Bāb 33, Nr. 4215); al-Buhārī, Șaḥịh, I, 352 (Faḍāìl almadīna, Bāb 9, Nr. 1914) und III, 1439 (al-Fitan, Bāb 27, Nr. 7210); Muslim, Șahìh, II, 1242 (al-Fitan wa-ašrāt as-săe a, Bāb 24, Nr. 7577).

$\left.{ }^{71}\right)$ as-Suyūṭi , Kašf, 140-41.

72) Ibid., 142 .

${ }^{73)}$ as-Suyūṭī, Kašf, 146; al- ${ }^{e} I m a \bar{d} \mathrm{~d}$, Hawqala, 65.

${ }^{74)}$ as-Suyūṭī, Kašf, 213. 
Erhebung von Zinsen. ${ }^{75}$ Die Autoren untermauerten diese Kausalität, indem sie zeigten, dass die Erde das erste Mal in der Menschheitsgeschichte nach der Tötung Abels durch Kain gebebt hatte. Erdbeben waren somit eine von mehreren Möglichkeiten, neben Sonnen- und Mondverfinsterungen, starken Stürmen sowie fitan (gewalttätige interne Auseinandersetzungen zwischen Muslimen), um die göttliche Strafe auszudrücken.

Die Betonung der Strafdimension von Erdbeben durch die unterschiedlichen Autoren diente auch dazu, Interpretationen zu verwerfen, die Erdbeben als malăhim (Vorzeichen) sahen, mittels derer das Schicksal einzelner Individuen, Dynastien, Gruppen, Regionen etc. gedeutet werden könne. Die wahrscheinlich im 4./10. oder 5./11. Jahrhundert entstandene Abhandlung Malhamat Dāniyāl führte so zum Beispiel aus, dass Erdbeben (je nach dem Monat, in dem sie auftraten) auf Krieg, Aufstände, Epidemien, sinkende Preise, Wasserknappheit, Missernten, ausreichende Regenfälle, gute Ernten, weitere Erdbeben und Tyrannei hindeuten. ${ }^{76}$ Ibn al-Ğazzār wandte sich in seiner Abhandlung scharf gegen jene, die „Katastrophen“ (inklusive astronomische Phänomene) in dieser Art und Weise deuteten. ${ }^{77}$ Vielmehr betonte er, dass diese Katastrophen eine Ermahnung Gottes seien, das Verbotene zu unterlassen und das Gebotene zu verrichten. Die Tatsache, dass Ibn al-Ğazzār zu diesem Thema so explizit Stellung nahm, muss wohl im Zusammenhang damit gesehen werden, dass die Vorhersage mittels malăhim in der osmanischen Periode ihren Höhepunkt erreichte. ${ }^{78}$

Dass die Autoren Erdbeben vor allem als göttliche Mahnung oder Strafe für die Muslime ansahen, war nicht so selbstverständlich, wie es auf den ersten Blick scheint, da andere Katastrophenformen abweichend interpretiert werden konnten. So gab es durchaus in den religiösen Wis-

75) as-Suyūṭì, Kašf, 138-47; Ibn al-Ğazzār, Taḥș̄n, 144, 145; al- 'mādī, Hawqala, 64, 65 .

$\left.{ }^{76}\right) \mathrm{Zu}$ diesem Werk vgl. A. Fodor: Malhamat Daniyal, in: G. KÁldy-NaGY (Hg.): The Muslim East. Studies in Honour of Julius Germanus, Budapest: Lorańd Eötvös University, 1974, 85-159 (mit Reproduktion einer im Irak gedruckten Version des Textes). Im frühneuzeitlichen Europa findet sich die Interpretation von Naturkatastrophen als Vorzeichen ebenfalls in entsprechenden Wunderbüchern, Flugblättern und Flugschriften, hierzu vgl. R. Ze LLE R: Naturkatastrophen zwischen Kuriosität, Sensation und religiöser Interpretation. Zur Semiotik von Naturkatastrophen, in: C. Pfister/S. Summermatter (Hg.): Katastrophen und ihre Bewältigung. Perspektiven und Positionen, Bern/Stuttgart/Wien 2004, 79-100.

77) Ibn al-Ğazzār, Tahṣīn, 155.

${ }^{78)}$ T. FAHD: La divination arabe, Paris 1966, 224-28. 
senschaften verwurzelte Autoren, die Katastrophen nicht ausschließlich als göttliche Mitteilungen ansahen. Die Abhandlung zu Hungersnöten von al-Maqrīzī, der etwa 50 Jahre vor as-Suyūṭī gewirkt hatte, verstand diese Katastrophe kaum als göttliches Zeichen. Vielmehr diskutierte er vor allem die Gründe für die wirtschaftlichen Krisen, die zu den Hungersnöten im frühen 9./15. Jahrhundert geführt hatten und schlug u. a. eine Geldreform zur Vorbeugung weiterer vergleichbarer Katastrophen vor. ${ }^{79}$

Bemerkenswert ist aber, dass alle Abhandlungen Erdbeben in erster Linie als Strafe ansahen, wie es zusammenfassend in einem had $\underline{\underline{t}} \underline{\text { deutlich }}$ wird, das die Autoren zitierten: „Gott hat für meine Gemeinschaft in dieser Welt drei Strafen vorbereitet: Mord, Erdbeben und gewaltsame Auseinandersetzungen". ${ }^{80}$ Dagegen wurden Erdbeben nur selten als Gnade Gottes verstanden, so etwa in der oben zitierten Phrase, die Erdbeben „,als Ermahnung für die Gottesfürchtigen, als Akt der Barmherzigkeit für die Gläubigen und als Strafe gegen die Ungläubigen " beschrieb. ${ }^{81}$ Direkt im Anschluss hieran findet sich in as-Suy ūṭ̄ auch die einzige Stelle in den Abhandlungen (ein had $\underline{\underline{t}}$ quds̄̄), die den Tod der gläubigen Opfer eines Erdbebens explizit als „Märtyrertum“ bezeichnete. Doch es war as-Suyūṭī selbst, der in einem längeren Exkurs die Interpretation eines hadīt verwarf, demzufolge Erdbeben ein „Segen“ für die Gläubigen seien. Im Abschluss dieses Exkurses betonte er, dass Erdbeben ausschließlich als Strafe zu verstehen seien. ${ }^{82}$ Die Pest, um eine andere bedeutende Katastrophenform anzuführen, wurde dagegen durchaus als Barmherzigkeit Gottes (rahma) gesehen, die von den Frommen als Ausdruck seines Willens ertragen werden sollte. Ihre (frommen) Opfer waren Märtyrer, die den gleichen Stand hatten, wie die Märtyrer des ğihād, da ihr Tod durch

$\left.{ }^{79}\right)$ Von den 81 Seiten der hier verwendeten Ausgabe umfassen 34 Seiten historische Berichte vorheriger Hungersnöte. Auf 41 Seiten diskutiert der Autor Gründe für wirtschaftliche Krisen, gibt einen Überblick über monetäre Krisen der Vergangenheit, nennt Preise für verschiedene Güter und schlägt Lösungsmöglichkeiten für Reformen des Geldsystems vor.

$\left.{ }^{80}\right)$ as-Suyūṭī, Kašf, 140 und Ibn al-Ğazzār, Tahṣinn, 145.

$\left.{ }^{81}\right)$ as-Suyūṭī, Kašf, 142 und Ibn al-Ğazzār, Tahṣinn, 145, 146. Lediglich ' ${ }^{\top}$ '’ iša wurde in den Abhandlungen ähnliche Worte zugeschrieben, mit denen sie Erdbeben als Strafe für die Ungläubigen und ,als Barmherzigkeit, Segen und Ermahnung für die Gläubigen " bezeichnete (as-Suyūṭi, Kǎsf, 138 und Ibn al-Ğazzār, Tah șin, 144). Vereinzelt findet sich diese Sichtweise auch in Chroniken, so zum Beispiel in Ibn al-Qalānisī, der schrieb, dass das Erdbeben im Jahre 552/1157 ein Ausdruck der göttlichen Güte und Barmherzigkeit sowie seines Erbarmens sei (Ibn al-Qalānisī, Dayl, 344).

${ }^{82}$ ) as-Suyūṭī, Kařf, 144-45. 
die Ungläubigen und sittenlosen Muslime verursacht sei, gegen die Gott die Pest herab gesandt habe. ${ }^{83}$

\section{Erdbebenabhandlungen: Verhaltensanweisungen}

Der längste Abschnitt in al- ${ }^{c}$ Imādīs Abhandlung bezog sich darauf, wie man in spiritueller Hinsicht richtig auf Erdbeben reagieren solle. Dieses Thema nahm auch in den beiden anderen Abhandlungen eine recht prominente Stelle ein. ${ }^{84}$ So berichtete Ibn al-Ğazzār bereits in seiner einleitenden Liste zeitgenössischer Aussagen zu Erdbeben von Reaktionen wie dem rituellen Gebet und der Flucht in offenes Gelände. Die Bedeutung des Themas für die Autoren wird auch darin deutlich, dass sich zwei der Abhandlungen in ihren Titeln auf Verhaltensanweisungen bezogen. Al- Imādīs Das Aussprechen der Formel „Es gibt keine Stärke und keine Macht außer durch Gott" bei Erdbeben, wies auf den entsprechenden normativen Abschnitt in seiner Abhandlung hin. Ibn al-Ǧazzār spielte mit dem Titel Die Befestigung der Heimstätten gegen das Schrecken der Erdbeben auf eine Passage seines Textes an, in der er die moralische und spirituelle Reinheit und Standhaftigkeit als Mittel gegen Erdbeben pries. ${ }^{85}$ In den entsprechenden Abschnitten diskutierten die Autoren etwa die Fragen, ob das rituelle Gebet (salāt) anlässlich von Erdbeben einzeln oder in Gemeinschaft stattzufinden habe, ob es während oder nach dem Erdbeben durchzuführen sei, wie viele Sequenzen es zu umfassen habe, ob ein bloßes Bittgebet $\left(d u^{c} \bar{a}^{3}\right)$ ausreichend sei oder ob das spezifische Gebet für Verfinsterungen (salāt al-hussuf) auch bei Erdbeben durchzuführen sei.

Alle hier betrachteten Autoren behandelten die Frage, ob bei einem Erdbeben die Flucht aus Gebäuden erlaubt sei. Diese Diskussion stand implizit im Zusammenhang mit dem Verbot, Pestgebiete zu verlassen oder zu betreten. ${ }^{86}$ Das Verbot war in Hinsicht auf die Pest sowohl auf theologische Überlegungen, die die Vorbestimmung Gottes betonten, als

${ }^{83)}$ Conrad, Plague Chronicles, 89; B. Shoshan: „Waba $\vec{a}-1$. In the mediaeval Islamic world up to the $10^{\text {th }} / 16^{\text {th }}$ century “, in: Encyclopaedia of Islam. New Edition, 11 Bd., WebCD edition (Leiden 2003); Dols, Black Death, 112-15; J. SuBLET: La peste prise aux rêts de la jurisprudence. Le traité d'Ibn Ḥağar al-Asqalānī sur la peste, in: Studia Islamica 33 (1971), 141-49, hier: 144-45.

${ }^{84}$ ) as-Suyūṭī, Kašf, 148-56; Ibn al-Ğazzār, Tahṣ̄n, 148 (Z. 9)-151 (Z. 7); al'Imādī, Hawqala, 61 (Z. 21)-63 (Z. 21).

$\left.{ }^{85}\right)$ al- Imādì, Hawqala, 62; Ibn al-Ǧazzār, Tahșīn, 148-49.

${ }^{86)}$ Vgl. für Pestepidemien Dols, Black Death, 22. 
auch auf praktische Überlegungen, die ein weiteres Ausbreiten der Krankheit zu begrenzen suchten, zurückzuführen. ${ }^{87}$ Die Autoren gaben für den Kontext von Erdbeben eine pragmatische Antwort, indem sie mittels Analogieschlüssen die Flucht als empfehlenswert (mustahabb) gestatteten. ${ }^{88}$

Der umfangreichste Teil der Passagen zu den Verhaltensanweisungen besteht aber darin, dass ein unmittelbarer Verhaltenskodex entwickelt wird. Dabei wurde postuliert, dass die erste Reaktion das rituelle Gebet $(s a l \bar{a} t)$ zu sein habe. Dies war grundsätzlich individuell durchzuführen und sollte nicht von einer Predigt ( $h \bar{u} t \underline{b a})$ begleitet sein. ${ }^{89}$ Damit grenzten die Autoren das Gebet anlässlich von Erdbeben gegen das Gebet bei Sonnen- und Mondfinsternissen und dem Bittgebet für Regen ab, die beide durch hadīte eine gewisse Normierung erfahren hatten. Auf das Gebet sollte weiterhin möglichst eine freiwillige Almosengabe (sadaqa) folgen. Bei Erdbeben, die länger andauerten, war an zwei Tagen in der Woche (Montag und Donnerstag) zu fasten. ${ }^{90}$ Als letzte spirituelle Reaktion empfahlen die Autoren, Invokationen wie takbīr und tasbīh auszusprechen.

Auffällig an diesen Passagen ist, dass sich die diskutierten Fragen nahezu ausschließlich im Rahmen des Erlaubten bewegten. Ausführlichere Abschnitte diskutierten glaubenspraktische Fragen, wie zum Beispiel bei as-Suyūṭi, der umfangreichen Platz für die Frage reservierte, wie viele Körperbeugungen und Prostrationen beim rituellen Gebet anlässlich von Erdbeben angemessen seien. Mögliche heterodoxe oder volkstümlichere Praktiken wurden in den Texten selten erwähnt. Die Tatsache, dass die Erdbebenabhandlungen (und auch die Chroniken) diese Praktiken im Zusammenhang mit Erdbeben nicht erwähnten ist bemerkenswert, da sie zum Beispiel von Pestausbrüchen bekannt sind. Hier waren magische und okkultistische Praktiken wie etwa die Verwendung von magischen Quadraten, Talismanen oder Amuletten weit verbreitet. ${ }^{91}$

Dass die Menschen auf Erdbeben tatsächlich in vielfältiger Art und Weise reagierten, zeigen Texte jener Verfasser, die nicht zu dem engen Kreis

${ }^{87)}$ Ibid., 110.

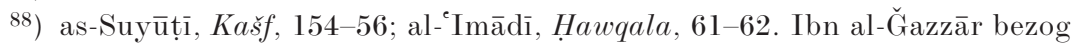
keine eindeutige Position, pries aber diejenigen, die sich der Vorherbestimmung Gottes anheim gaben (Ibn al-Ğazzār, Tahşinn, 148).

${ }^{89}$ ) as-Suyūṭī, Kašf, 152-53; Ibn al-Ğazzār, Tahṣinn, 148; al- Imādī, Hawqala, 63.

$\left.{ }^{90}\right)$ as-Suyūṭī, Kašf, 151; Ibn al-Ğazzār, Taḥșinn, 150; al- Imādī, Hawqala, 62.

$\left.{ }^{91}\right)$ Dols, Black Death, 121-42. 
der Autoren von Chroniken und Erdbebenabhandlungen gehörten. Der tagebuchartige Text des Damaszener Barbiers al-Budayrī im 12./18. Jahrhundert beschrieb zum Beispiel, wie immer wieder Vorhersagen zu Erdbeben kursierten, die Damaskus zerstören würden. Diese Vorhersagen

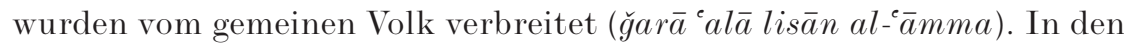
folgenden Versen wurden die eigentlichen Urheber dieser Vorhersagen aber als rawäfid bezeichnet, Individuen schiitischer Ausrichtung, die heterodoxer Praktiken bezichtigt wurden. Sie verbreiteten diese Lügen, obwohl man wisse, dass das Verborgene (al-gayb) dem menschlichen Wissen nicht zugänglich sei. ${ }^{92}$ Auch im Damaskus des 7./13. Jahrhunderts spielten solche Vorhersagen eine entscheidende Rolle, um eine Grundstimmung von Katastrophe und Angst hervorzurufen. ${ }^{93}$

Al-Budayrīs Text zeigt wiederholt, dass die herrschenden Eliten seiner Periode die Notwendigkeit sahen, das gesellschaftliche Handeln zu regulieren. Anlässlich eines lang anhaltenden Erdbebens im Jahre 1173/1759 etwa befahl der Gouverneur ein allgemeines Fasten für drei Tage und ein anschließendes gemeinschaftliches Gebet in der MuṣallāMoschee außerhalb von Damaskus. ${ }^{94}$ Diese Anweisungen folgten wiederum exakt dem normativen Rahmen, den die Gelehrten in den Abhandlungen abgesteckt hatten. Die Autoren von Erdbebenabhandlungen beschränkten sich bei der Nennung historisierender Beispiele ebenfalls darauf, wahlweise das Vorbild des umayyadischen Kalifen ${ }^{\mathrm{e}} \mathrm{Umar}$ b. 'Abd al-Azīz (r. 99/717-101/720) oder des vierten ,rechtgeleiteten“ Kalifen 'Alī anzuführen. Diese sollen anlässlich von Erdbeben vorgeschrieben haben, zu festgesetzten Zeiten zu fasten, freiwillige Almosengaben zu entrichten und den Koran zu rezitieren. ${ }^{95}$

Der zuvor hinsichtlich der Erdbebenberichte in Chroniken herausgearbeitete Diskurs der Kontinuität tritt in den Erdbebenabhandlungen in diesen Passagen zu Verhaltensanweisungen am deutlichsten zu Tage: Der Blick wurde auf orthopraktische Verhaltenweisen gerichtet und abweichende Praktiken wurden nahezu vollständig ausgeschlossen. Hierdurch können die Veränderungen, die die Katastrophe hervorrief, marginalisiert und die Bedeutung des Einschnitts gemindert werden. Ibn al-Ğazzār formulierte diese Zielsetzung der Erdbebenabhandlungen explizit in derjenigen Passage, in der er seinen Text gegen as-Suyūṭis Abhandlung

$\left.{ }^{92}\right)$ al-Budayrī, Hawādit, 98.

${ }^{93}$ ) L. Pouzet: Damas au XIIe/XIIe siècle. Vie et structures religieuses d'une métropole, Beirut ${ }^{2} 1991,382$.

${ }^{94)}$ al-Budayrī, Hawādit, 100.

$\left.{ }^{95}\right)$ as-Suyūṭi $, K a \check{s} f, 151$; Ibn al-Ǧazzār, Tahṣinn, 151. 
abgrenzte und dessen ausführliche Liste von Einzelberichten missbilligte: „Dann fährt as-Suyūṭ̄i fort, Erdbeben in Miṣr, al-Qāhira, Madīna, Makka, wo der südliche Pfeiler zerstört wurde, und anderes zu beschreiben, dessen Erwähnung sich nicht ziemt. In dem, was wir dagegen erwähnt haben, finden sich Anspielungen, die beruhigen. Die klare Erwähnung von Katastrophen, insbesondere wenn sie eine nach der anderen behandelt werden, gehört nicht zu den Gaben des Schönen, noch zu den ziemlichen Traditionen. ... Das erhabene Ziel ist vielmehr, durch die Erwähnung dessen, was vorgefallen ist, zu trösten und durch [die Erwähnung] dessen, was einigen Völkern widerfuhr, zu heilen. Denn in einigen [wenigen] Erwähnungen verbirgt sich eine vollständige Ermahnung für den Wissenden. “96

Ibn al-Ğazzār kritisierte as-Suyūṭī einerseits dahingehend, dass die Erwähnung einiger Beispiele ausreiche, um die Hauptaussage zu vermitteln, so dass as-Suyūṭis Liste keinen Wert für den Leser habe. Andererseits - und dies ist an dieser Stelle der entscheidende Kritikpunkt - warf er as-Suyūṭi vor, unziemliche Aspekte zu erwähnen. Was er darunter verstand, macht Ibn al-Ğazzār deutlich, indem er betont, sein Text solle im Gegensatz zu as-Suyūṭī der Beruhigung, der Tröstung und der Heilung dienen. Ziel war es, dem durch die Katastrophe verunsicherten Leser - alle drei Abhandlungen wurden ja jeweils direkt in Folge eines Erdbebens verfasst - Gewissheit darüber zu geben, dass trotz der materiellen Schäden die ihm vertraute spirituelle und soziale Ordnung weiterhin Bestand habe.

\section{Berichte in Chroniken zum Erdbeben von 702/1303}

Ausgehend von der eingangs postulierten engen Verbindung zwischen Chroniken und Erdbebenabhandlungen soll nun gezeigt werden, in welcher Art und Weise sich die Hauptaussagen der Abhandlungen hinsichtlich der Themen Kosmologie, Bedeutung von Erdbeben und Verhaltensanweisungen in der Chronistik niederschlugen und wie dadurch die Einbettung dieses Genres im Diskurs der Kontinuität Ausdruck fand. Hierfür werden Berichte aus ägyptischen Chroniken zum Erdbeben des Jahres 702/1303 diskutiert, das den östlichen Mittelmeerraum betraf, Schäden von der Peloponnes-Halbinsel über Palästina bis nach Ägypten verursachte und im gesamten nordafrikanischen Raum zu spüren war. Trotz dieser weiten geographischen Ausdehnung führte es anscheinend nur in einer begrenzten Anzahl von Fällen zur vollständigen Zerstörung von Gebäuden und

\footnotetext{
96) Ibn al-Ğazzār, Tahșinn, 154.
} 
forderte keine größeren Opferzahlen. Eine vertiefte Diskussion der Darstellung von Erdbeben in Chroniken bietet sich anhand dieses Beispiels an, da die Berichte zu diesem Erdbeben ungewöhnlich umfangreich sind.

Für dieses Erdbeben sind vier ausführlichere Berichte zeitgenössischer Chronisten überliefert: Baybars al-Manșūrīs (st. 725/1325) Zubdat al-fikra, an-Nuwayrīs (st. 733/1333) Nihāyat al-arab, Ibn ad-Dawādārīs (st. n. 736/1335) Kanz ad-durar und eine von Zetterstéen edierte anonyme Chronik. ${ }^{97}$ Autoren folgender Epochen verwandten in erster Linie diese vier Berichte als Vorlagen für ihre Chroniken. Da sie das Material nicht nur zitierten, sondern auch redaktionell deutlich überarbeiteten und ausbauten, geben sie ebenfalls einen Einblick in die Art und Weise, wie Chronisten Erdbeben im Laufe der Zeit in unterschiedliche narrative Zusammenhänge stellten. Aufgrund der Ausführlichkeit sind hier insbesondere al-Maqrīzīs (st. 845/1441) Kitāb as-sulūk und al-Aynīs (st. 855/1451) ' Iqd al-ğumān relevant. ${ }^{98}$ Während gezeigt werden kann, wie die Texte dieser zweiten Gruppe von denen der zeitgenössischen Autoren abhängen, ist dies für das Verhältnis der Texte innerhalb der jeweiligen Gruppe nicht möglich. Gerade die zeitgenössischen Autoren, deren Lebensdaten teilweise nur unzureichend bekannt sind, zitierten und paraphrasierten sich gegenseitig. Hier ist es oft unklar, welcher Text die Vorlage war, beziehungsweise ob diesen Passagen ein weiterer unbekannter Text zugrunde lag. ${ }^{99}$

Nicht alle Autoren von Chroniken im 8./14. und 9./15. Jahrhundert maßen dem Erdbeben von 702/1303 jedoch größere Bedeutung zu und beschrieben es daher auch nur in knappen Passagen. Die wohl kürzeste Version findet sich bei Ibn Tağrībirdī (st. 874/1470), dessen Bericht sich aus-

$\left.{ }^{97}\right)$ Ibn ad-Dawādārī: Kanz ad-durar wa-ğāmic al-gurar, 9 Bd., hg. v. H. RoEMer, et al., Kairo u.a.: Sāmī al-Hुānğì [in Komm.] u.a., 1960-94, IX, 100-106; an-Nuwayrī: Nihāyat al-arab fī fun̄̄n al-adab, Bd. XXXII, hg. v. Fahīm Muhạmmad ${ }^{e}$ Ulwī Š́ ALtū T, Kairo: Wizārat at-Taqāfa wa-al-Iřsād al-Qawmī, 1998, 57-59; Baybars al-Manșūrī ad-Dawādār: Zubdat al-fikra fī ta'rīh al-hiğra, hg. v. D. S. RIChards, Beirut/Berlin 1998, 378-79; Anonym., hg. v. K. V. Zetterstéen: Beiträge zur Geschichte der Mamlūkensultane in den Jahren 690-741 der Hiğra nach arabischen Handschriften, Leiden 1919, 126-28.

${ }^{98}$ ) al-Maqrīzì: Kitāb as-sulūk li-márifat duwal al-mulūk, 4 Bd., hg. v. Muhammad M. AZ-ZiYĀDA et al., Kairo: Maṭba at Lağnat at-ta’líf wa-at-tarğama waan-našr/Maṭb at Dār al-kutub, 1934-75, I, 942-45; al-'Aynī, '́ Iqd, IV, 260-65.

${ }^{99}$ ) So ist zum Beispiel die Anfangspassage Ibn ad-Dawādārīs weitgehend identisch mit dem Bericht an-Nuwayrīs, ohne dass die Frage der gegenseitigen Abhängigkeit, beziehungsweise der Verwendung einer gemeinsamen Vorlage zu klären wäre. 
schließlich auf materielle Schäden und den Wiederaufbau konzentriert: „In [diesem Jahr] gab es in Mișr und al-Qāhira ein großes Erdbeben, das zahlreiche Minarette und viele Gebäude, darunter Moscheen und Wohnhäuser, zerstörte. Deshalb waren die Offiziere und die Verwalter der Stiftungen lange mit der Reparatur und dem Wiederaufbau der Lehranstalten (madāris), Moscheen und sogar des Leuchtturms von Alexandrien beschäftigt, die von ihm verwüstet worden waren. "100

\section{Zeitgenössische Autoren}

Von den zeitgenössischen Autoren beschrieben, wenn auch in knappen Passagen, Baybars al-Manșūrī und Anonym. neben den materiellen Schäden die Reaktionen der Menschen auf das Erdbeben. Hierbei griffen sie auf den Topos der Flucht aus den Gebäuden und der Anflehung Gottes zurück. ${ }^{101}$ Baybars al-Manșūrīs Text ist im Weiteren recht unprofiliert. Er nannte, ebenso wie die anderen Autoren, Schäden in anderen Regionen, insbesondere Alexandrien, und die geringen Opferzahlen in Ägypten. Das charakteristische Element seiner Beschreibung war die „Joghurtverkäufer-Anekdote“, die von der wundersamen Rettung eines Joghurtverkäufers berichtete, der nach drei Tagen unter den Trümmern seines Ladens lebend gefunden wurde. Allerdings erfüllte diese Anekdote erst bei späteren Autoren, insbesondere al-Maqrīzì, eine weitergehende narrative Funktion, während sie sich bei Baybars al-Manșūrī isoliert zwischen Berichten zu den Wirkungen des Erdbebens in anderen Regionen befand.

Anonym., der sich zum Zeitpunkt des Erdbebens im oberägyptischen Munyat Ibn al-Hașīb aufgehalten hatte, ließ den Reaktionen der Menschen einen kurzen Augenzeugenbericht folgen und ging dann auf die Bedeutung dieses Erdbebens ein. Hierfür zitierte er eine huṭba, die er anlässlich des Erdbebens verfasst hatte. Diese Mahnrede stellte den Bezug zum Jüngsten Tag her und benannte die Sündhaftigkeit der Menschheit als Ursache für die Katastrophe, die Anlass zur Reue sein sollte und durch die Gott gezielt die Missetäter treffe sowie die Frommen ausspare. ${ }^{102}$ Bei dieser Predigt handelt es sich um mehr als die bloße Aneinanderreihung standardisierter Textbausteine, wie es auf den ersten Blick scheinen mag. Der Autor spielte damit auf die konkrete Ursache des Erdbebens an, das

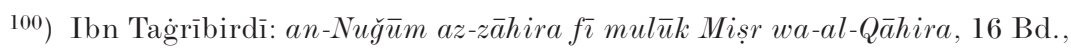
Kairo: Wizārat at-țaqāfa wa-al-iršād al-qawmī, 1963-72, VIII, 201.

$\left.{ }^{101}\right)$ Baybars al-Manșūrī, Zubdat, 378; Anonym., 136.

102) Anonym., 137-38. 
andere Autoren, wie im Folgenden zu sehen sein wird, explizit auf das Fehlverhalten der mamlūkischen Elite zurückführten.

Ibn ad-Dawādārīs und an-Nuwayrīs Text legten ein vollständiges Desinteresse hinsichtlich der Reaktionen der Menschen an den Tag und beschäftigten sich vielmehr mit den materiellen Schäden in Kairo, denen sie die genaue Nennung derjenigen Offiziere folgen ließen, die sich beim Wiederaufbau zerstörter Gebäude hervortaten. Während an-Nuwayrī seinen Bericht mit dieser Aufzählung abschloss, wandte sich Ibn ad-Dawādārī aber noch der Bedeutung des Erdbebens zu, das er mittels der von Anonym. verfassten Mahnrede einführte. Er gab sich aber mit der Erklärung des Erdbebens als göttliches Strafgericht nicht zufrieden und ging als einziger der hier untersuchten Autoren zu kosmologischen Überlegungen über. Hierfür zitierte er Passagen aus al-Qazwīnīs Kosmographie hinsichtlich der pneumatischen Erdbebentheorie, der Rolle von Erdbeben bei der Entstehung von Bergen und Ebenen, sowie dem Einfluss astronomischer Phänomene auf geologische Änderungen. Ibn ad-Dawādārīs Text vereinte somit sowohl gottesbezogene als auch naturkundliche Erklärungen, die er weitgehend unkommentiert nebeneinander stehen ließ. Hierdurch schwächte er die Strafdimension des Erdbebens, die bei Anonym. zentral ist, deutlich ab. Der koptische Chronist al-Mufaḍdal b. Abī al-Faḍāil (fl. 8./14. Jhd.) führte diese Tendenz in seiner Beschreibung des Erdbebens von 702/1303 noch weiter aus, indem er Ibn ad-Dawādārīs naturkundliche Passagen gekürzt übernahm, aber keinerlei Gottesbezug herstellte. ${ }^{103}$

\section{Autoren des 9./15. Jahrhunderts}

Bei al-Maqrīzī und al-Aynī, die auf eine Vielzahl von Vorlagen zurückgreifen konnten, entwickelten sich die Berichte über das genannte Erdbeben zu zunehmend komplexeren Narrativen. In diesen Erzählungen war das Verhalten der Menschen weiterhin von untergeordneter Bedeutung, und kosmologische Aspekte wurden nicht mehr erwähnt. Das zen-

$\left.{ }^{103}\right)$ Ibn ad-Dawādārī, Kanz, IX, 104-10B6; al-Mufaḍdal b. Abī al-Faḍāàil:

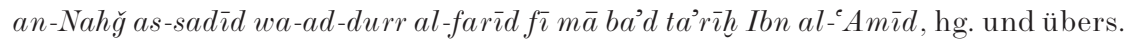
v. E. Blochet: Moufazzal Ibn Abil-Fazaïl. Histoire des sultans mamlouks, (Patrologia orientalis Bd. 20, Fasc. 1), Paris 1928, 89-90. Eine gewisse Wertung liegt bei Ibn ad-Dawādārī vor, wenn er die naturkundlichen Erklärungen mit den Worten einleitete: „Diejenigen, die sich Philosophen nennen (al-mutafalsifīn), führen aus ...". 
trale Thema waren nun die bei den zeitgenössischen Autoren weniger ausgeprägten Überlegungen zur Bedeutung der Katastrophe. Indem die späteren Autoren diesen thematischen Schwerpunkt wählten und auch unterschiedliche erzählerische Mittel einsetzten, war das Erdbeben von $702 / 1303$ zunehmend den Regelmäßigkeiten des Diskurses der Kontinuität unterworfen.

Al-Maqrīzī und al-Aynī führten die bei Baybars al-Manșūrī und Anonym. bereits erwähnten Reaktionen der Einwohnerschaft Kairos weiter aus: Die Menschen flohen aus der Stadt, übernachteten im Freien, beziehungsweise in Zelten und verbrachten die Nacht mit Gebeten, in denen sie Gott um Gnade anflehten. Bei al-Maqrīzī findet sich weiterhin der einzige Hinweis auf deviantes Verhalten, die Plünderung verlassener Häuser. Spirituell abweichendes Verhalten hingegen fehlte hier wie auch in den anderen Berichten erwartungsgemäß vollständig. ${ }^{104}$ Im Vordergrund stand nun die Bedeutung des Erdbebens als göttliches Strafgericht, das aufgrund des Fehlverhaltens von Teilen der mamlūkischen Elite auf Ägypten niedergekommen war. Al-Aynī gab als Quelle für diese Interpretation den verlorengegangenen Text des Historikers Mūsā alYūsufī (st. 759/1358) an. ${ }^{105}$ Aus den zugänglichen Zitaten lässt sich die Struktur dieses Ursprungstexts allerdings nicht rekonstruieren, so dass nur die Überarbeitungen späterer Autoren herangezogen werden können.

Al-Maqrīzì leitete seinen Bericht - wohl ebenfalls mit Bezug auf alYūsufī - mit den Gründen für dieses göttliche Strafgericht ein: „In ihm [dem Monat Šawwāl des Jahres 702] ereignete sich ein starkes Erdbeben. Dies [passierte], da sich in al-Qāhira und Miṣr während der Errichtung der Festungen und der Feierlichkeiten Lasterhaftigkeiten ... zutrugen, die nicht beschrieben werden können."106 Diese Vorwürfe bezogen sich darauf, dass prominente mamlūkische Offiziere eine Reihe von hölzernen Festungen entlang der Paraderoute des Sultans errichtet und reich verziert hatten. Hiermit feierten sie den entscheidenden Sieg, den die Mamlūken nahe dem syrischen Šaqhab im vorhergehenden Monat über die Armee Maḥmūd Ġāzāns (st. 713/1304) errungen hatten und der den ilhānidischen Ambitionen in der Region ein Ende bereitete. An den kritisierten mehrwöchigen Feierlichkeiten nahm sowohl das gemeine Volk als auch die mamlūkische Elite teil.

104) al-Maqrīzī, Sul̄̄k, I, 942-43; al-'Aynī, ' Iqd, IV, 261, 263-64.

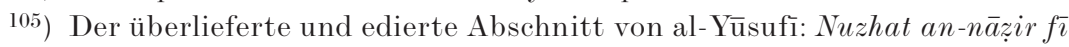
sīrat al-malik an-Nāṣir, hg. v. Aḥmad ḤıțAYṬ, Beirut: 'Ālam al-Kutub, 1986 enthält lediglich die Jahre 733-38.

$\left.{ }^{106}\right)$ al-Maqrīzī, Sulūk, I, 942. 
Al-Maqrīzī wiederholte gegen Ende seines Berichtes die Strafdimension des Erdbebens, indem er dessen Wirkung erneut auf diejenigen beschränkte, die sich sündhaft verhalten hätten: „In diesem [Erdbeben] war eine Wohltat (lutf) Gottes an seine Diener. Denn sie ließen von Einigem ab, was sie in den Tagen der Feierlichkeiten an unsittlichem Vergnügen und Lasterhaftigkeit begangen hatten. Unter ihnen waren welche, die von dieser [Lasterhaftigkeit] gänzlich abließen aufgrund der zahlreichen Nachrichten, die aus den fränkischen Territorien und anderen Gebieten über die Folgen dieses Erdbebens eintrafen. "107

Hierauf folgen zwei Anekdoten, die dadurch, dass sie im Anschluss an diese Kritik stehen ihre narrative Bedeutung erlangen. Als erstes führte der Autor die „Schriftstück-Anekdote“ an, in der einer der mächtigsten Offiziere seiner Zeit die zentrale Rolle spielte. Baybars II al-Ğašnikīr (st. 709/1310) war nach einer steilen Karriere in der mamlūkischen Elite seit 698/1299 einer der beiden Regenten des noch jungen Sultans Nāṣir adDīn Muhammad I b. Qalāwūn. Nach zehnjähriger Regentschaft konnte er selbst das Sultansamt übernehmen, wurde aber nach weniger als einem Jahr von Nāṣir ad-Dīn aus dem Amt vertrieben und kurz darauf in Kairo hingerichtet. In der Anekdote stieß er bei Reparaturarbeiten an der aus der fāțimidischen Zeit stammenden und während des Erdbebens beschädigten Hākimī-Moschee am Fuße des Minaretts auf wundersame Weise auf eine Hand, die noch „frisch“ war. Um das Handgelenk war ein Schriftstück mit Zeilen gewickelt, die den Zeitgenossen unverständlich blieben. ${ }^{108}$

Mit dieser Anekdote verstärkte al-Maqrīzī einerseits die Kritik an den Mitgliedern der Elite, die nicht von der Lasterhaftigkeit abließen und denen die göttliche Botschaft des Erdbebens ebenso unverständlich blieb wie das Schriftstück, das infolge des Erdbebens gefunden wurde. Andererseits spielte er mit dem Schriftstück auf das weitere Schicksal al-Ğašnikīrs an, der von dem „rechtmäßigen“ Sultan kurz nach der Machtergreifung vertrieben und schließlich hingerichtet wurde. Der Vergleich zu al-'Aynī, der die Anekdote ebenfalls erwähnte, lässt ihre Funktion bei al-Maqrīzì deutlicher werden. Al-Aynī konzentrierte sich auf den Entschluss al-Ğašnikīrs, beschädigte Teile des Minaretts abreißen zu lassen, da er hoffte, dass al-Ḥākim für einen solchen Katastrophenfall dort Gold für den Wiederaufbau deponiert hatte. Der Autor ließ offen, ob dort in der Tat Gold gefunden wurde, pries aber al-Ğašnikīr für den Wiederaufbau und die zahlreichen zusätzlichen Stiftungen, die er in der Moschee einrichtete. Er erwähnte das Schriftstück lediglich am Ende der Anek-

107) Ibid., I, 945 .

108) Ibid. 
dote kurz, ohne dass es die zentrale Rolle inne hatte, die al-Maqrīzī ihm zuschrieb. ${ }^{109}$ Al-Maqrīzī rückte in seiner Erzählung zudem al-Ğašnikīr in den Mittelpunkt, der das Schriftstück allein gefunden hatte, während es in al-Aynīs Version von „ihnen“ gefunden wurde.

Al-Maqrīzī verstärkte seine der „Schriftstück-Anekdote“ zugeschriebene Botschaft durch die direkt folgende und deutlich kontrastierende „Joghurtverkäufer-Anekdote“. Diese Erzählung - die einzige, die bereits bei früheren Autoren zu finden ist - schloss seinen Bericht zum Erdbeben ab. Als jemand, der im Gegensatz zu dem Regenten nicht an den Missetaten beteiligt war, die das Erdbeben verursacht hatten, wurde der Joghurtverkäufer auf wundersame Weise nach drei Tagen aus den Trümmern seines Ladens gerettet: Er wurde „lebend herausgeholt und das Unheil hatte ihm keinen Schaden zugefügt."110 Die Unversehrtheit der unbeteiligten Menschen hatte al-Maqrīzì bereits zuvor in der „MelkerAnekdote" betont, bei der ein Melker durch das Beben bei der Arbeit überrascht wurde. Sowohl er als auch die Kuh, die er gerade molk, wurden in die Luft gehoben. Sie kamen aber wieder unversehrt auf den Boden zurück. Die göttliche Gnade gegenüber den Unschuldigen verstärkte die Anekdote noch dadurch, dass hierbei nicht ein Tropfen der Milch seines Melkeimers verschüttet wurde. ${ }^{111}$

Al-Aynīs Text war in der Beschreibung des Erdbebens als Strafgericht Gottes für die von der militärischen und politischen Elite durchgeführten Feierlichkeiten wesentlich expliziter. Nach der Erwähnung der verübten Sünden fuhr er fort: „Es gab in der Stadt niemanden von den Großen der Haushalte (akābir al-buyūt), den Offizieren und anderen Notabeln $\left(a^{c} y \bar{a} n\right)$, der nicht sein Haus in Begleitung von Dienern, Bediensteten und Aufsehern (qahramānāt) verlassen hätte. ... Gott versiegelte ihre Herzen gemäß seiner Vorherbestimmung und seines Beschlusses, so dass er auf sie das Erdbeben herabsandte. "112 Durch diese klare Zuschreibung der Bedeutungsebene sah al-Aynī keine Notwendigkeit, Rückgriff auf das literarische Element der Anekdoten zu nehmen, die bei al-Maqrīzī zentral waren. Die „Melker-Anekdote“ fehlte vollständig und die „Joghurtverkäufer-Anekdote" war im langen Zitat aus Baybars al-Manșūrīs Bericht eingebettet, wo sie keine herausgehobene narrative Rolle für den Bericht über das Erdbeben spielte, die mit al-Maqrīzīs Text vergleichbar wäre. Weiterhin diente die „Schriftstück-Anekdote“ bei ihm deutlich anderen

\footnotetext{
109) al-'Aynī, ${ }^{\mathrm{C}} \mathrm{Iqd}, \mathrm{IV}, 264-65$.

${ }^{110)}$ al-Maqrīzì, Sul̄̄k, I, 945.

111) Ibid., I, 943-44.

112) al-Aynī, ${ }^{\mathrm{C}} I q d, \mathrm{IV}, 263$.
} 
Zielen, nämlich der Lobpreisung der Wiederaufbaubemühungen der mamlūkischen Elite. Dementsprechend wiederholte al-Aynī auch die Strafdimension des Erdbebens nicht erneut, sondern schloss seinen Text vielmehr mit den zahlreichen von Offizieren eingerichteten Stiftungen.

Aus der Diskussion der Berichte zum Erdbeben von 702/1303 wird deutlich, dass die Charakteristika der Erdbebenabhandlungen sich zwar in den Chroniken wiederfinden, die Chroniken aber auch ein eigenständiges Profil hatten. Ebenso wie die Autoren der Erdbebenabhandlungen betonten die Chronisten, dass Erdbeben ein Mittel göttlicher Kommunikation mit der muslimischen Gemeinschaft seien. Sie dienten als Sanktionen für abweichende Verhaltensweisen, Aufruf zur Reue und Ankündigung für den Jüngsten Tag. ${ }^{113}$ Jedoch wurde diese Strafdimension in den Chroniken unterschiedlich stark betont. Während sie bei Baybars alManșūrī nur angedeutet wurde, arbeiteten sie Anonym. und Ibn ad-Dawādārī durch die Mahnrede deutlicher heraus. Es waren aber erst die späteren Autoren al-Aynī und al-Maqrīzī, die diesen Aspekt in den Mittelpunkt stellten. Es bedurfte wohl der zeitlichen Distanz, um die narrativen Möglichkeiten der Berichte in dieser Hinsicht weiter auszuarbeiten und anekdotisches Material zu entwickeln, das bei den zeitgenössischen Autoren noch weitgehend fehlte. Auffällig ist, dass Ibn ad-Dawādārī die Einbeziehung der Strafdimension umkommentiert zu den naturkundlichen Erklärungsansätzen stehen ließ, die die Autoren der Erdbebenabhandlungen sämtlich scharf ablehnten. Die Formulierung des exklusiven theologischen Deutungsanspruchs der Katastrophe in den Abhandlungen schloss also nicht die fortdauernde Existenz pluraler Deutungen in anderen Literaturgattungen aus.

In den Abhandlungen wurde die Sichtweise auf Erdbeben als Strafe, nicht als Gnade Gottes, betont. In den Chroniken spielte der letztere Aspekt ebenfalls eine untergeordnete Rolle. Lediglich al-Maqrīzī betonte, dass Erdbeben als Anstoß zur Umkehr und somit als eine göttliche Wohltat angesehen werden könnten. Die anderen Autoren, die auf diesen Aspekt eingingen, sahen lediglich die Kürze des Erdbebens als eine Gnade an, was aber die grundsätzliche Strafdimension kaum modifizierte. ${ }^{114}$

Am deutlichsten tritt die Parallelität zwischen Erdbebenberichten in Chroniken und Erdbebenabhandlungen in Form des Diskurses der Kon-

113) Der Bezug zum Jüngsten Tag findet sich in den Chroniken zum Beispiel an folgenden Stellen: Baybars al-Manșū rī, Zubdat, 378; Anonym., 136; Ibn ad-Dawādārī, Kanz, 102; al-Aynī, ' Iqd, IV, 260. Bezeichnenderweise fehlt dieser Bezug bei al-Maqrīzī, der am deutlichsten die Strafdimension herausarbeitet.

114) Baybars al-Manșūrī, Zubdat, 378; Anonym., 136; al-'Aynī, ' Iqd, IV, 260. 
tinuität heraus. Auch die Berichte zu dem Erdbeben von 702/1303 erhielten kaum tatsächliche Reaktionen der Bevölkerung auf die Katastrophe. Wurden sie erwähnt, so verwendeten die Autoren - abgesehen von den bei al-Maqrīzi kurz erwähnten Plünderungen - den Topos „Schrecken Flucht außerhalb der Stadtmauern - Bittgebete“. Die Autoren erwähnten vielmehr die Schäden an Gebäuden ausführlich (wobei betont wurde, dass diese wie es ein Autor formulierte „besser wiederaufgebaut wurden als sie zuvor waren"115) oder sie stellten die Ebene göttlicher Kommunikation in den Mittelpunkt.

Die Berichte zum Erdbeben von 702/1303 verdeutlichen somit beispielhaft die eingangs postulierten engen Beziehungen zwischen Erdbebenabhandlungen und Chroniken. Diese Beziehungen zeigen, dass zum Verständnis der narrativen Charakteristika der Chroniken auch die Betrachtung der normativen Abhandlungen notwendig ist. Bei beiden Quellengattungen ist dementsprechend gleichermaßen die Frage zu stellen, was diese Texte in ihrer Zeit bedeuteten und welche Sinnebenen sie dem zeitgenössischen $\mathrm{Pu}$ blikum vermittelten. Ebenso wie bei Berichten zu politischen Ereignissen kommentierten die Chroniken geschichtliche Prozesse, die sie oberflächlich gesehen lediglich als chronologisch geordnete Ansammlung von Ereignissen beschrieben. Erdbebenberichte in Chroniken sind somit funktional nicht von normativen Erdbebenabhandlungen zu trennen.

Dabei mindert der den beiden Literaturgattungen unterliegende Diskurs der Kontinuität und die unterschiedlichen narrativen Strategien der Texte nicht notwendigerweise den Quellenwert der Chroniken. Dieser Diskurs und die narrativen Elemente erklären vielmehr den Aufbau dieser Berichte und die Entscheidungen der Autoren, welche Aspekte einzubeziehen, beziehungsweise auszuschließen waren. Durch diese Sichtweise auf die Berichte in den Chroniken ist es möglich, das spärliche faktische Material in Bezug auf soziale Veränderungen und spirituelle Reaktionen nicht als Mangel, sondern als konstitutives Charakteristikum des Genres zu verstehen, dessen Autoren weniger an einer faktischen Darstellung der Katastrophe, als an ihrer interpretatorischen Einordnung interessiert waren. Im Ergebnis kann also in Bezug auf die Frage nach der diskursiven Verortung von Erdbeben während der post-formativen Periode festgehalten werden, dass das der Katastrophe innewohnende Moment der Zäsur sowohl in Chroniken als auch in Erdbebenabhandlungen ausgeklammert oder mittels Topoi in stets normkonformes Handeln gewendet wurde.

115) Ibn ad-Dawādārī, Kanz, 101. 